\title{
The Cuprizone Model: Dos and Do Nots
}

\author{
Jiangshan Zhan ${ }^{1}$, Teresa Mann ${ }^{1}$, Sarah Joost ${ }^{1}{ }^{1}$, Newshan Behrangi ${ }^{1}$, Marcus Frank ${ }^{2} \oplus$ and \\ Markus Kipp 1,*(D) \\ 1 Institute of Anatomy, Rostock University Medical Center, Gertrudenstrasse 9, 18057 Rostock, Germany; \\ Jiangshan.Zhan@med.uni-rostock.de (J.Z.); Teresa.Mann@med.uni-rostock.de (T.M.); \\ Sarah.Joost@med.uni-rostock.de (S.J.); Newshan.Behrangi@med.uni-rostock.de (N.B.) \\ 2 Medical Biology and Electron Microscopy Center, Rostock University Medical Center, Strempelstraße 14, \\ 18057 Rostock, Germany; Marcus.Frank@med.uni-rostock.de \\ * Correspondence: Markus.Kipp@med.uni-rostock.de; Tel.: +49-381-494-8401
}

Received: 25 February 2020; Accepted: 27 March 2020; Published: 31 March 2020

check for updates

\begin{abstract}
Multiple sclerosis (MS) is a chronic inflammatory demyelinating disease of the central nervous system. Various pre-clinical models with different specific features of the disease are available to study MS pathogenesis and to develop new therapeutic options. During the last decade, the model of toxic demyelination induced by cuprizone has become more and more popular, and it has contributed substantially to our understanding of distinct yet important aspects of the MS pathology. Here, we aim to provide a practical guide on how to use the cuprizone model and which pitfalls should be avoided.
\end{abstract}

Keywords: multiple sclerosis; cuprizone model; histological analyses

\section{Introduction}

Multiple sclerosis (MS) is a frequent disease of the central nervous system (CNS) affecting predominantly young adults. On the histopathological level, the disease is characterized by focal white and grey matter demyelination, caused by the interplay of brain resident cells (such as microglia and astrocytes) and peripheral immune cells (such as lymphocytes and monocytes). Besides demyelination, the focal and diffuse invasion and (re-) activation of these immune cells results in damage to nerve cells [1]. Of note, virtually all neuronal subcellular structures can be destroyed in the brains of MS patients, including axons, dendrites or synaptic spines [2-5]. Eventually, entire nerve cells can get lost $[5,6]$. On the clinical level, distinct disease courses can be distinguished: at the beginning of the disease, most patients suffer from the sudden occurrence of new neurological symptoms, which usually disappear after several weeks [7]. This initial disease course is called relapsing remitting MS (RRMS), which means that symptoms appear (i.e., a relapse) and then fade away, either partially or completely (i.e., remitting). By definition, during the RRMS disease phase, the level of clinical disability remains stable in between two relapses. After several years (10-15 years), the frequency of relapses decreases, and the patients clinically deteriorate independent of the relapses. This so-called secondary progressive MS (SPMS) course is thus characterized by chronically progressive clinical worsening over time, with or without superimposed relapses. In about $15 \%$ of the patients, the disease is characterized by neurologic worsening (accumulation of disability) from the onset of symptoms, without early relapses or remissions, called primary progressive MS (PPMS).

On the pathological level, the RRMS disease course is characterized by recurrent episodes of inflammatory white matter demyelination. These inflammatory events are probably driven by peripheral, autoreactive immune cells, which invade the CNS parenchyma via the blood-brain or blood-liquor barrier. Consequently, drugs that interfere with leukocyte travelling and invasion, such 
as Natalizumab or Fingolimod, significantly decrease the frequency of relapses during the RRMS disease phase.

Although patients can clinically recover completely from a relapse, this does not necessarily mean that there is no residual damage to the brain parenchyma. Such residual damage can be triggered by (i) instant and (ii) delayed neuronal damage. (i) From pre-clinical and post-mortem studies, there is ample evidence that focal inflammatory demyelination induces neurodegeneration, such as axonal transection or neuronal apoptosis $[4,5,8]$. In the classical autoimmune model of MS, experimental autoimmune encephalomyelitis (EAE), encephalitogenic T helper $17\left(\mathrm{Th}_{17}\right)$ cells have been shown to form direct physical contacts with neurons during the development of inflammatory lesions [8]. These $\mathrm{Th}_{17}$ cells eventually induce a marked, localized, and partially reversible raise in intra-axonal $\mathrm{Ca}^{2+}$ concentrations that might lead to axonal transection or neuronal soma degeneration. Of note, $\mathrm{Th}_{1}$ cells were much less efficient at killing neurons through this mechanism, but have been shown to contribute to neuronal damage by releasing tumor necrosis factor-related, apoptosis-inducing ligand, and by activating the pro-apoptotic mediator caspase-3 in neurons [9]. (ii) Besides such immediate harmful events, delayed degenerative processes can be triggered by the focal lesions. For example, if the focally destroyed myelin sheath cannot be repaired (i.e., remyelination) different biochemical mechanisms can trigger delayed axonal degeneration among an increased energy demand from impulse conduction along excitable demyelinated axons [10], lack of axonal trophic support by oligodendrocytes [11], a lethal rise in intra-axonal calcium levels [12], or a higher vulnerability of demyelinated axons against cytotoxic substances. Beyond this, white and grey matter areas distant to the focal lesion side show subtle yet important signs of tissue damage, such as microglia activation, abnormal blood vessels, increased expression of genes related to proteolytic processing, or a decreased expression of genes regulating oligodendrocyte survival $[13,14]$. Since these white and grey matter regions are not "normal" (i.e., healthy) they are described as normal-appearing white and grey matter (NAWM and NAGM, respectively). To conclude, although neurological function can fully recover after a relapse, some slow-burning degenerative processes are triggered by focal lesions that are not yet apparent during the early disease phase. These slow-burning degenerative processes are believed to be driven by local, innate immune cells. Of note, the results of a recent clinical trial suggests that Siponimod, which modulates sphingosine-1 phosphate receptor activities [15], might ameliorate such delayed neurodegenerative processes by modulating sphingosine-1 phosphate receptor signaling expressed in astrocytes, microglia, and oligodendrocytes [16].

During progression of the disease, two fundamental pathogenetic factors change: first, the activity of the adaptive immune system decreases, which clinically results in a lower frequency of clinically detectable relapses [17]. Why the adaptive (and maybe also the innate) immune system becomes less active during disease progression is currently unknown, but immunosenescence probably plays an important role [18]. Second, the slow-burning degenerative process reaches a certain threshold and becomes clinically apparent. Two mechanisms likely play a role in the delayed clinical manifestation of this slow-burning neurodegeneration. On the one hand, the function of damaged or degenerated neurons can be carried from neighboring neurons, a process called neuronal plasticity $[19,20]$. On the other hand, the destruction of single or a group of neurons does not necessarily result in overt clinical deficits. This is maybe best illustrated by the fact that as many as $80 \%$ of the dopaminergic neurons may be lost before clinical symptoms are apparent in affected Parkinson patients. Another, more plastic example might be helpful: imagine in front of you is a container with 1000 balls. If somebody takes out one single ball it is rather unlikely that this will be recognized. However, if just two balls are left, most people will certainly recognize if another ball is taken out of the container. During the RRMS disease stage, the initial loss of neuronal structures is not recognized by the patient or, in other words, does not lead to overt clinical deficits. Later during the disease, at the transition phase from RRMS to SPMS, when many neurons are already lost, the subsequent damage to additional neuronal structures results in accumulating and overt clinical deficits. 
To summarize this part of the article, adaptive immunity is the driving force during RRMS, whereas brain resident innate immune cells are believed to cause tissue damage during the progressive phase of the disease. Beyond that, the loss of the myelin sheath makes axons more vulnerable, and therefore, failure of remyelination aggravates disease progression. Current strategies to ameliorate or even halt disease progression in SPMS and PPMS patients are (i) the strengthening of neuroprotective pathways, (ii) amelioration of diffuse innate immune responses, and (iii) the induction of remyelination.

\section{Characteristics of the Cuprizone Model}

In the following chapter we will briefly introduce the cuprizone model, a toxin-induced demyelination model [21,22]. We will then focus on technical aspects of this model, and thus hope to provide the unexperienced scientist guidelines how to work effectively with this pre-clinical MS tool.

Oral intoxication with the copper-chelator cuprizone induces oligodendrocyte apoptosis within a few days, which is closely followed by the activation of the innate immune cells in the brain, i.e., astrocytes and microglia, finally leading to demyelination of distinct white and grey matter brain areas. Although minor damage to the blood-brain barrier has been described in this model [23], cells of the adaptive immune system, particularly T- and B-cells, are believed to play a non-dominant role during cuprizone-induced demyelination [24,25]. This model thus reflects several important characteristics of the progressive MS disease course. With the cuprizone model, two main aspects related to the MS pathology can be investigated: first, mechanisms underlying innate immune cell-driven myelin and axonal degeneration, and second, remyelination of the demyelinated axons.

To induce acute demyelination, young adult mice are intoxicated with cuprizone per os for 5 to 6 weeks. In our hands, consistent and intense demyelination is obtained after a 5 week intoxication protocol $(0.25 \%$ cuprizone, mixed into ground rodent chow). If animals are provided normal chow after week 5 (i.e., acute demyelination), spontaneous endogenous remyelination occurs. In case the cuprizone intoxication period is prolonged (i.e., chronic demyelination), this endogenous regenerative process is severely disturbed [26-28]. Most labs, including ours, perform a 12-13 week cuprizone intoxication period to obtain chronically demyelinated lesions. Although remyelination occurs after a chronic cuprizone-induced demyelination as well, myelin repair is significantly slower $[26,28]$. It is important to notice that after acute cuprizone-induced demyelination, one should not investigate the potency of a pharmaceutical compound to induce remyelination, but rather can assess its potency to accelerate an ongoing remyelinating process, or to inhibit it $[29,30]$. To study remyelination in the non-supportive environment, one can either apply the chronic cuprizone model or, as demonstrated several years ago, one can use aged animals [31], probably because of the induction of senescence-associated inhibitors of oligodendrocyte differentiation $[32,33]$.

After having provided a general introduction to the cuprizone model, we now will discuss histopathological characteristics during the different experimental intoxication periods.

\subsection{Week 1}

As demonstrated by several groups, the first apoptotic oligodendrocytes appear days after initiation of the cuprizone intoxication protocol (See Figure 1A for a schematic illustration of the course of cuprizone-induced demyelination and Figure 1B, as well as Figure 2, for the appearance of apoptotic oligodendrocytes). In a recently published work, we compared the mRNA expression levels in the white matter tract corpus callosum isolated from control mice and animals intoxicated with cuprizone for 2 days by gene array analysis [34,35]. As soon as $48 \mathrm{~h}$ after initiation of the cuprizone intoxication, we found the expression levels of numerous mRNAs increased or decreased. The most impressive finding was that those mRNA species which were found to be reduced in cuprizone-intoxicated mice are reported to be mostly expressed by oligodendrocytes. As shown in Table 1 and Figure 3, 22 out of the top 25 downregulated mRNAs were found to be enriched in oligodendrocytes (cellular enrichment was retrieved from Brain RNA-Seq database [36]). In contrast, the top 25 upregulated mRNAs were 
found to be enriched in various cell types, such as astrocytes, microglia/macrophages, and endothelial cells. Interestingly, two out of the top 25 induced genes were found to be enriched in oligodendrocyte progenitor cells (i.e., Serpina3n and Fam46a), suggesting that oligodendrocyte progenitor cells (OPCs) might also participate in inflammatory responses, as previously suggested [37]. Alternatively, it might be that mature oligodendrocytes re-express proteins expressed during oligodendrocyte development, as suggested for astrocytes [38], or that OPCs are activated early during the course of cuprizone-induced demyelination. Nevertheless, this rough gene array analysis indicates that (i) cuprizone predominantly impairs mature oligodendrocyte homeostasis, and (ii) that other glia cells, such as astrocytes and microglia, but also endothelial cells and OPCs, are activated early in the intoxication period. After a 1 week cuprizone intoxication period, oligodendrocyte loss and microglia/astrocyte activation are clearly evident. The loss of oligodendrocytes can immunohistochemically be investigated by various antibodies. Our lab most commonly uses either anti-oligodendrocyte transcription factor 2 (OLIG2) or anti-adenomatous polyposis coli gene clone CC1 (APC or CC1) antibodies. Both can be reliably used to quantify the loss of mature oligodendrocytes during the early cuprizone intoxication period. However, one must take into consideration two important things: First, anti-OLIG2 antibodies are not specific for mature oligodendrocytes, but are expressed as well in OPCs. However, during early cuprizone-induced intoxication (i.e., after week 1 ) OPCs are not yet proliferating, and thus, the loss of anti-OLIG2 ${ }^{+}$cells is a good estimate for the extent of cuprizone-induced mature oligodendrocyte damage. Second, there have been some reports suggesting that $\mathrm{CC} 1$ is not just expressed by mature oligodendrocytes, but that anti-CC1 antibodies can also label activated astrocytes [39,40]. For the cuprizone model at least, CC1 expression in $\mathrm{GFAP}^{+}$astrocytes has been ruled out by the Stangel's lab [41], suggesting that CC1 is a suitable marker to stain cells of oligodendroglial origin in this model. As demonstrated in Figure 1B (right image), almost all $\mathrm{CC}^{+}$cells co-express the oligodendrocyte lineage marker protein OLIG2. Alternatively, anti-OLIG2/CC1 double labelling can be performed to quantify the loss of mature oligodendrocyte cell numbers. In that case, OLIG2 ${ }^{+} / \mathrm{CC}^{+}$cells can be considered to be mature oligodendrocytes, whereas $\mathrm{OLIG}^{+} / \mathrm{CC}^{-}$cells represent pre-mature ones (white arrowheads in Figure 1B, right image).

(A)

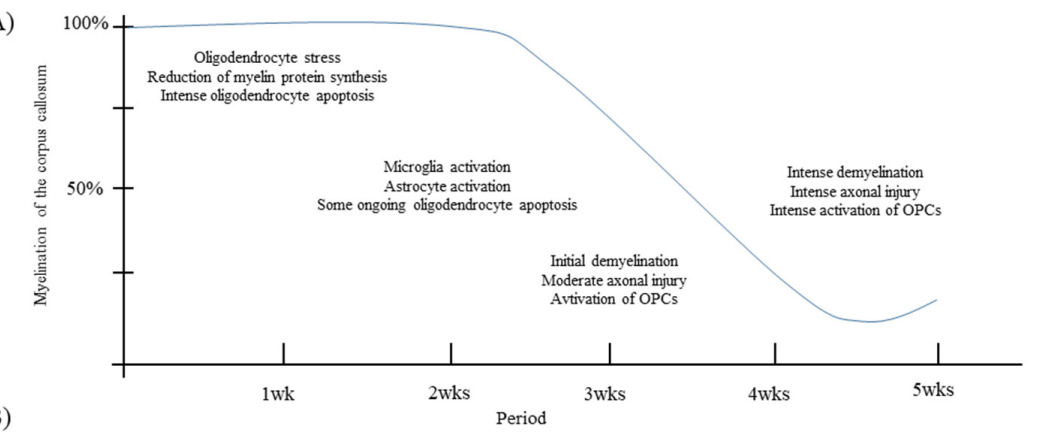

(B)
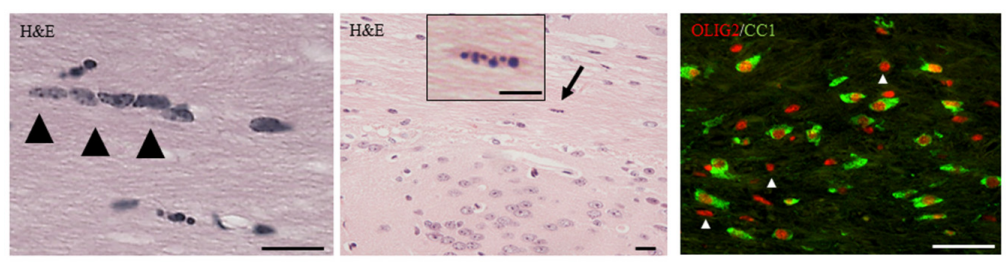

Figure 1. Hallmarks of the cuprizone model. (A) Schematic drawing illustrating pathological hallmarks during the course of cuprizone-induced demyelination. The blue line illustrates the levels of myelination. (B) The left image illustrates interfascicular oligodendrocytes (arrowheads) in the corpus callosum of a control mouse. The center image illustrates the appearance of an apoptotic cell (arrow) after 1 week of cuprizone intoxication. The right image illustrates mature OLIG ${ }^{+} / \mathrm{CC}^{+}$oligodendrocytes and pre-mature OLIG2 ${ }^{+} / \mathrm{CC}^{-}$oligodendrocytes (white arrowheads). Scale bar $=10 \mu \mathrm{m}$. Abbreviations: oligodendrocyte transcription factor 2 (OLIG2), adenomatous polyposis coli gene clone CC1 (CC1). 


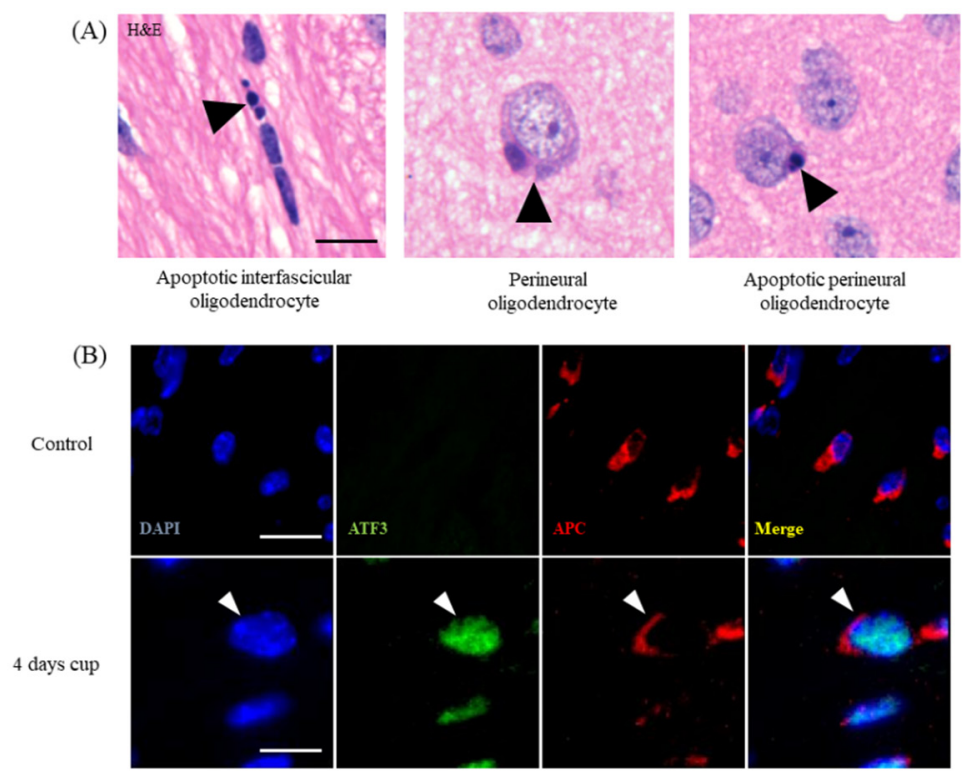

Figure 2. Oligodendrocyte stress and degeneration. (A) Different appearances of apoptotic oligodendrocytes in the white matter corpus callosum and grey matter cortex. The left image illustrates the appearance of an apoptotic cell (arrowhead) in the corpus callosum after 1 week of cuprizone intoxication. The center image illustrates a perineuronal oligodendrocyte in the cortex of a control mouse. The right image illustrates an apoptotic perineuronal oligodendrocyte. Perineuronal oligodendrocytes are also called "satellite oligodendrocytes". Scale bar $=10 \mu \mathrm{m}$. (B) Expression of the stress transcription factor ATF3 in control animals and in mice intoxicated with cuprizone for 4 days. White arrowheads highlight a stressed APC oligodendrocyte. Scale bar $=10 \mu \mathrm{m}$ (upper row) and $5 \mu \mathrm{m}$ (lower row). Abbreviations: activating transcription factor 3 (ATF3).

Table 1. Top 50 up- and down-regulated genes in 2 day cuprizone vs. control. Top 50 up-regulated (left column) and down-regulated (right column) genes in control versus 2 day cuprizone-intoxicated mice. Data are adopted from [35]. Note that most of the down-regulated genes are predominantly expressed by oligodendrocytes. We identified cell-specific gene expression using the online Brain RNA-seq database [36]. OPC: oligodendrocyte progenitor cell.

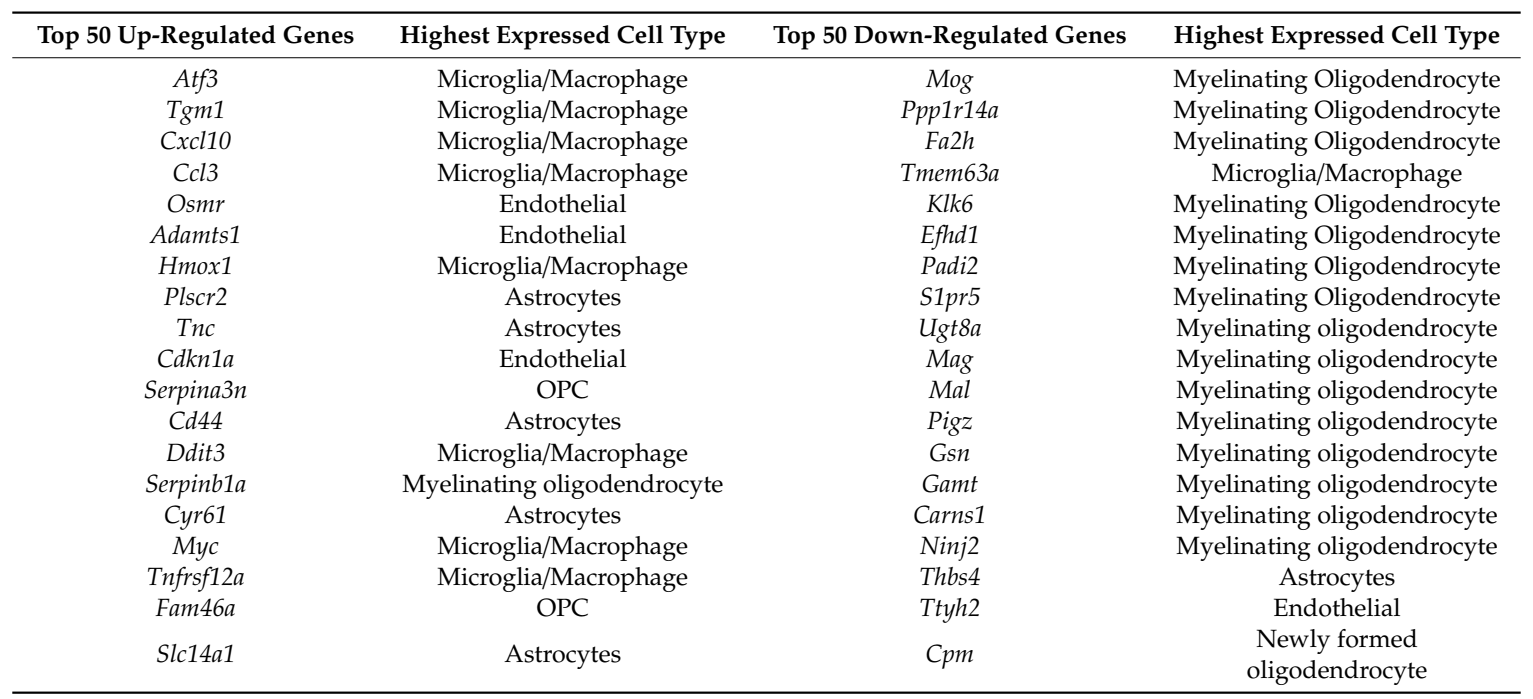


Table 1. Cont

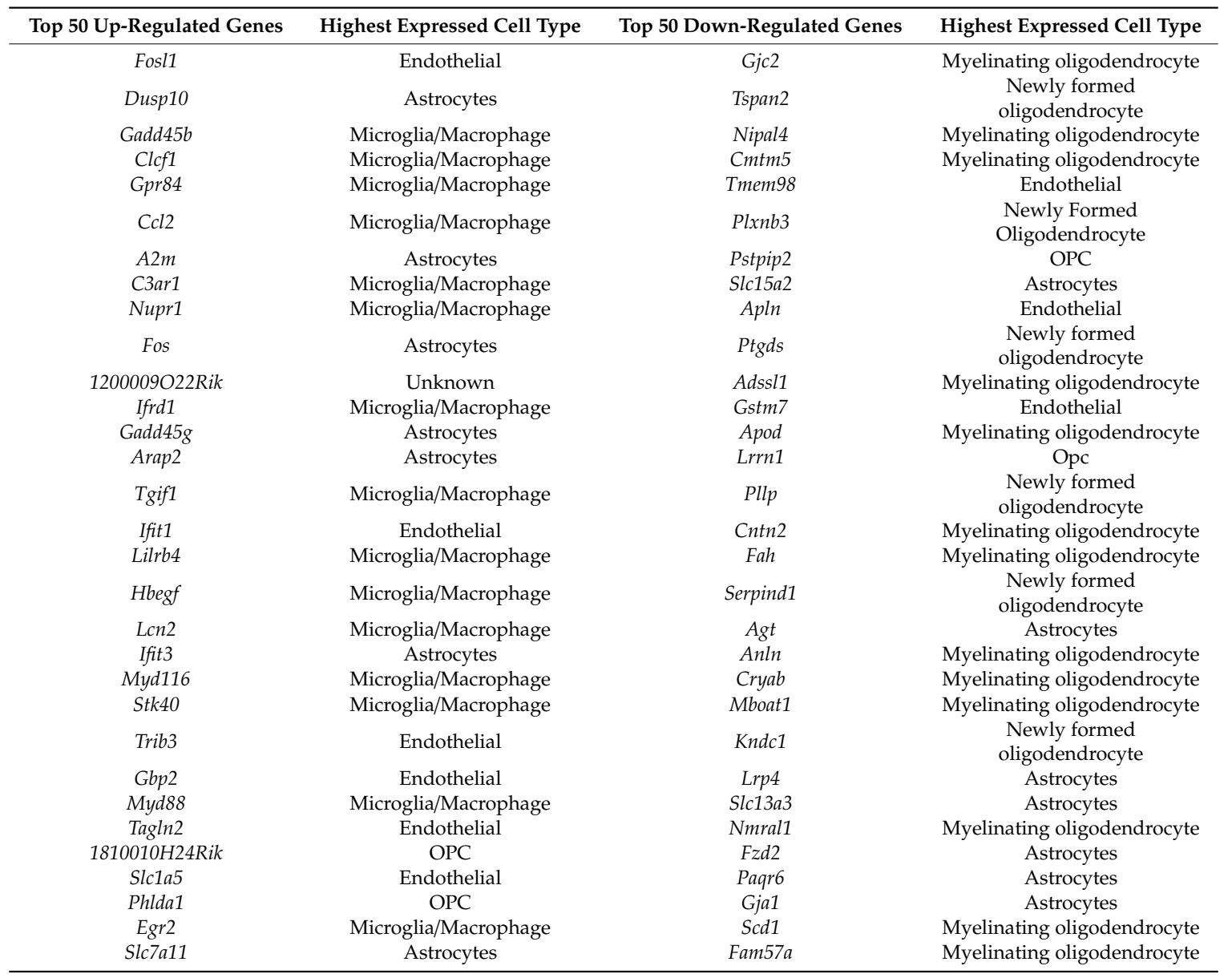

To visualize apoptotic oligodendrocytes is relatively simple, but due to increasingly strict requirements of reviewers and journals, it is sometimes a challenging task. The cheapest and simplest way to visualize apoptotic cells is the hematoxylin and eosin stain staining (H\&E). In coronal sections, oligodendrocytes can be identified by their characteristic positioning within the white matter. They are aligned in rows between the nerve fibers of the white matter, and are therefore called interfascicular oligodendrocytes (Figures 1B and 2A). As shown by Buschmann and colleagues, numerous apoptotic oligodendrocytes (i.e., condensed or fragmented nuclei; Figure 1B, arrow) can be seen already after 2 days of cuprizone intoxication [42]. Although double-labelling experiments with, for example, anti-active caspase 3 antibodies and an oligodendrocyte marker protein antibody can principally be performed, the blinded quantification of apoptotic bodies is, in our opinion, sufficient to estimate the extent of cuprizone-induced oligodendrocyte apoptosis. Of note, while the identification of apoptotic oligodendrocytes in the corpus callosum in H\&E-stained sections is relatively easy, the often perineuronal positing of cortical oligodendrocytes (Figure 2A) complicates the evaluation. However, we would like to point out that to the best of our knowledge, no other cell type than oligodendrocytes have been reported to degenerate during the early cuprizone intoxication period. Thus, apoptotic cells, howsoever visualized (H\&E, anti-active caspase 3, Terminal deoxynucleotidyl transferase dUTP nick end labeling (TUNEL), etc.), should be regarded to represent apoptotic oligodendrocytes, at least during the early cuprizone intoxication period. Recent studies from our lab showed that stressed, pre-apoptotic oligodendrocytes can be visualized by using antibodies directed against certain stress-related transcription factors, such as DNA damage-inducible transcript 3 protein (DDIT3 or CHOP) or activating transcription factor 3 (ATF3; see Figure 2B) [34]. Both stainings, thus, provide an elegant way to label the stressed oligodendrocyte population. 


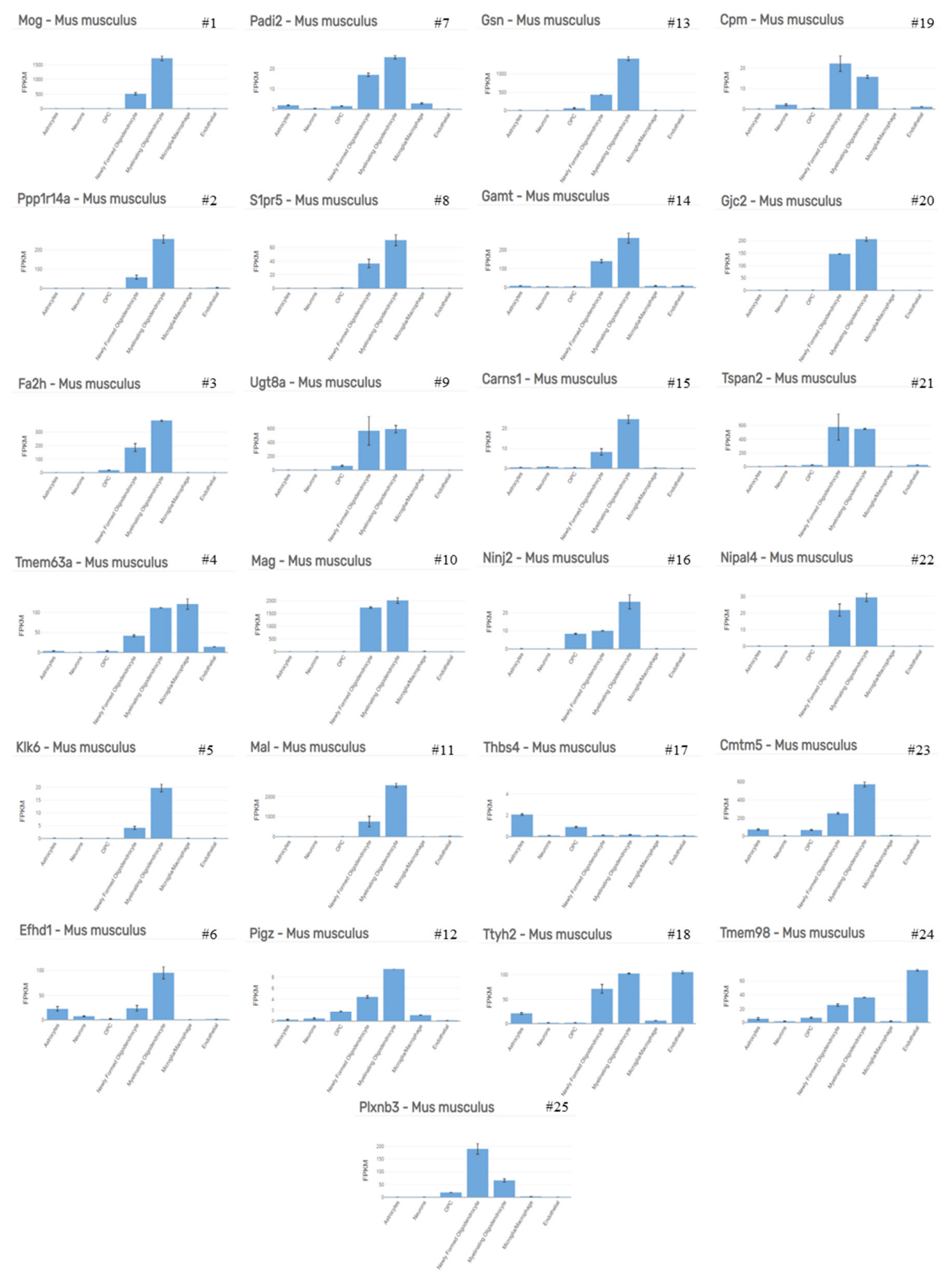

Figure 3. Cellular expression signature. Cellular enrichment of the top 25 downregulated mRNAs as shown in Table 1, retrieved from Brain RNA-Seq database [36]; \# represents rank number. Full-size image see Supplementary Figure S1. Abbreviations: myelin oligodendrocyte glycoprotein $(\mathrm{Mog})$, protein phosphatase 1 regulatory inhibitor subunit 14A (Ppp1r14a), fatty acid 2-hydroxylase (Fa2h), transmembrane protein 63A (Tmem63a), kallikrein related peptidase 6 (Klk6), EF-hand domain family member D1 (Efhd1), peptidyl arginine deiminase 2 (Padi2), sphingosine-1-phosphate receptor 5 (S1pr5), UDP galactosyltransferase 8A (Ugt8a), myelin-associated glycoprotein (Mag), myelin and lymphocyte protein (Mal), phosphatidylinositol glycan anchor biosynthesis class Z (Pigz), gelsolin (Gsn), guanidinoacetate N-methyltransferase (Gamt), carnosine synthase 1 (Carns1), nerve injury-induced protein 2 (Ninj2), thrombospondin 4 (Thbs4), tweety family member 2 (Ttyh2), carboxypeptidase M $(\mathrm{Cpm})$, gap junction protein gamma 2 (Gjc2), tetraspanin 2 (Tspan2), NIPA-like domain containing 4 (Nipal4), CKLF-like MARVEL transmembrane domain containing 5 (Cmtm5), transmembrane protein 98 (Tmem98), and plexin B3 (Plxnb3). 
To visualize the activation of microglia cells, most laboratories, including ours, use anti-ionized calcium-binding adapter molecule 1 (IBA1) antibodies. At the very beginning, we would like to stress that anti-IBA1 antibodies do not specifically label microglia cells, but rather represent an excellent tool to label monocytes and their derivatives. It is believed that microglia arise from yolk sac erythromyeloid precursors and migrate into the brain parenchyma during early development [43-45]. Although microglia represent a heterogeneous cell population [46], they still share several expression profiles with primitive and adult macrophages, including IBA1. Thus, anti-IBA1 antibodies stain microglia cells and invading monocytes. However, in the cuprizone model, and especially during the first week, peripheral monocyte recruitment is negligible, and therefore, numbers of anti-IBA $1^{+}$cells represent a good estimate for the extent of microglia activation. To quantify microgliosis during this early stage, blinded quantification of cell numbers is a reliable and commonly applied approach. The procedure to do so is relatively simple and straight forward: anti-IBA1 stained sections are digitalized, preferably using a 20-fold or greater objective, the region of interest is outlined (see Section 3.3 in this review article for more comments on the appropriate region of interest in the cuprizone model), and the number of cells with a clearly visible cell body is counted. Finally, the results are given as cells $/ \mathrm{mm}^{2}$. Of note, a nuclear counterstain, such as haematoxylin for bright-field microscopy or 4' ${ }^{\prime}$, 6-Diamidin-2-phenylindol (DAPI) for fluorescence-microscopy, should be used to ease the identification of cell bodies. Another frequently applied method is densitometric measurements of anti-IBA1 processed slides. Numerous protocols are available, and different open-source software packages, such as ImageJ, can be used. A less common, but as far as we are concerned, a very powerful and sensitive method to estimate microglia activation during early cuprizone-induced demyelination is the quantification of microglia morphology. As demonstrated in Figure 4B, following this strategy anti-IBA1 stained sections are digitalized, preferably using a 40-fold objective, and the maximum projection area (also called the convex hull; $A_{p}=$ yellow line in Figure $\left.4 \mathrm{~B}\right)$ and the cell area $\left(A_{c}=\right.$ brownish area in Figure $\left.4 \mathrm{~B}\right)$ are measured and related to each other. This results in the so-called ramification index $R_{i}=A_{p} / A_{c}$. Resting microglia have a relatively high maximum projection area $A_{p}$, but a relatively small cell area $A_{c}$. In that case, $R_{i}$ has a high value. During their activation, microglia retract their fine processes, and both the cell bodies and processes become hypertrophic. Activated microglia thus have a smaller maximum projection area $A_{p}$ but a bigger cell area $A_{c}$. In that case, $R_{i}$ approaches a value close to 1 (exactly 1 in the case of a perfectly round cell with equal values for $A_{p}$ and $A_{c}$ ). Such measurements are best performed in the deep layer cortex, since the morphology of cells, including microglia in the white matter tract corpus callosum, is somewhat biased by the axonal bundles oriented in parallel. Other ways to visualize the extent of microglia activation are the staining against commonly accepted microglia activation markers, such as MAC-3, also known as CD107b or lysosomal-associated membrane protein 2 (LAMP-2) [47].

To visualize the activation of astrocytes is, unfortunately, more challenging. Most labs use anti-glial fibrillary acidic protein (GFAP) antibodies to label activated astrocytes. Under physiological conditions, the expression levels of GFAP in the murine brain are relatively low, especially in the grey matter cortex region. Although filled with astrocytes, $\mathrm{GFAP}^{+}$cells are hard to delineate in the cortex of healthy mice. If so, $\mathrm{GFAP}^{+}$cells can mainly be found around bigger blood vessels or the superficial pia mater. There, they built up the glia limitans perivascularis and superficialis. Once activated, astrocytes up-regulate the expression of GFAP, and numerous cells become visible. To conclude, anti-GFAP antibodies do not label astrocytes, but rather activated astrocytes. Contrary to anti-IBA1 antibodies, which label the entire cell body and the fine, distal processes of microglia, anti-GFAP antibodies predominantly label the cell body and the thick primary processes of astrocytes. This fact makes morphological measurements somewhat challenging, and we do not recommend this as a standard method of choice to quantify the extent of astrocyte activation. Another circumstance that makes the analysis of astrocyte activation in anti-GFAP-processed brain slides challenging is that within the cell body, GFAP is not evenly distributed, but in many cases spares one site in the cell body (see Figure 5A, image 2). Thus, even in optimally processed sections it is sometimes hard to decide whether or not a GFAP ${ }^{+}$cell mass 
indeed represents the astrocytic cell body or simply a thick primary process. One possibility to work around this limitation is the use of transgenic mice, which express a fluorescent protein under the control of an astrocyte-specific promoter. We have recently applied this tool to decide whether or not the translocator protein (TSPO), a protein of the outer mitochondrial membrane, is expressed by astrocytes in the cuprizone model [48]. In this work, human glial fibrillary acidic protein-enhanced green fluorescent protein (hGFAP-eGFP) transgenic mice [49] were used to visualize entire astrocyte cell bodies and processes. To verify TSPO expression in astrocytes, brain slides from cuprizone-treated hGFAP-eGFP-mice were processed for anti-TSPO immunofluorescence staining. As demonstrated in Figure $5 \mathrm{~B}$, these mice express eGFP not only within their proximal astrocytic processes, but also within the fine distal processes of astrocytes. Applying this elegant tool, fluorescence labelling clearly showed that the anti-TSPO signal localizes to astrocyte cell bodies. Of note, other marker proteins are known for astrocytes, such as aldehyde dehydrogenase 1 family member L1 (ALDH1L1), vimentin, brain lipid binding protein (BLBP), or the calcium-binding protein S100ß, and can in principal be used to label astrocyte subpopulations.

(A)

(B)

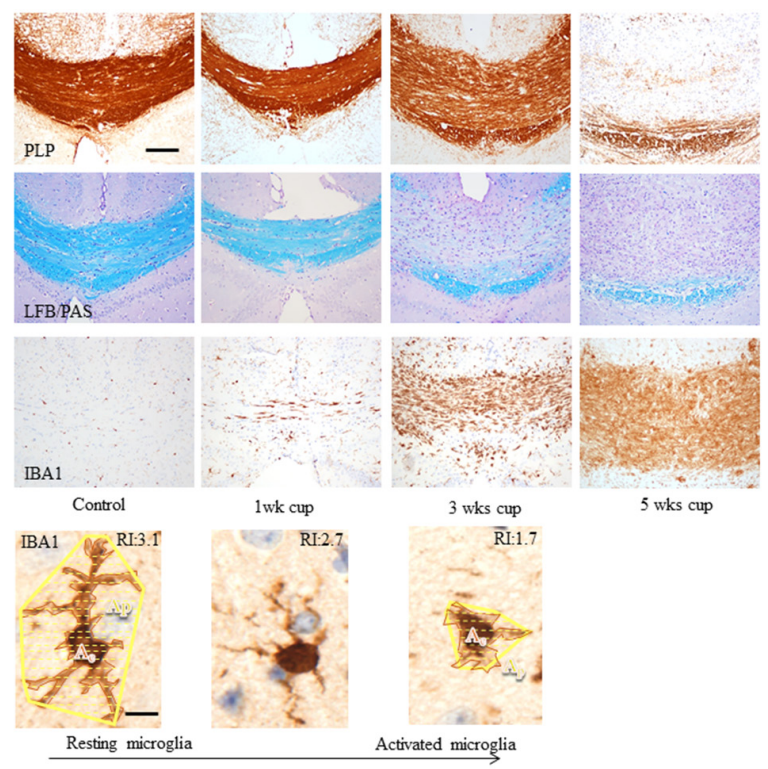

(C) Toluidine blue staining

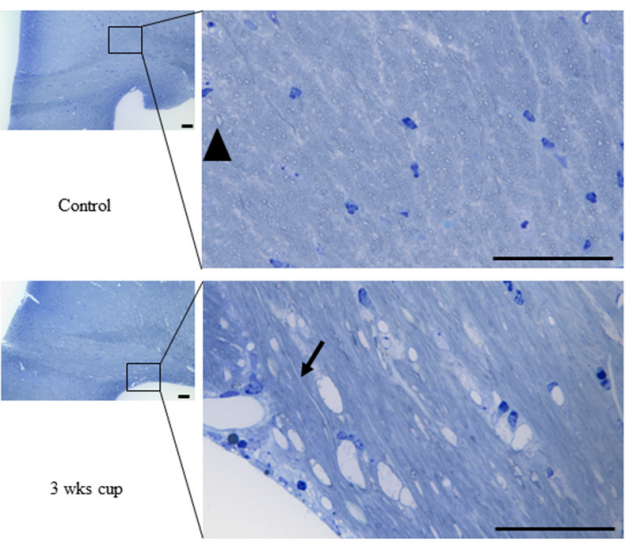

Figure 4. Demyelination and microgliosis. (A) Demyelination and microglia activation during the course of cuprizone-induced demyelination. Myelin was visualized by anti-PLP immunohistochemistry (upper row) and LFB/PAS (center row). Microglia activation was visualized by anti-IBA1 immunohistochemistry (lower row). Scale bar $=100 \mu \mathrm{m}$. (B) The principle of quantifying microglia morphology by calculating a ramification index. The maximum projection area $A_{p}$ and the cell area $A_{\mathcal{c}}$ are measured. Resting microglia have a relatively large maximum projection area $A_{p}$, but a relatively small cell area $A_{c}$. In that case, the ramification index $R_{i}$ has a high value. During their activation, microglia retract their fine processes, and both the cell bodies and processes become hypertrophic. In that case, $R_{i}$ approaches a value close to 1 (exactly 1 in the case of a perfectly round cell with equal values for $A_{p}$ and $A_{c}$ ). Scale bar $=5 \mu \mathrm{m}$. Abbreviations: myelin proteolipid protein (PLP), Luxol fast blue/periodic acid-Schiff stains (LFB/PAS), and ionized calcium-binding adapter molecule 1 (IBA1). (C) Toluidine blue-stained semithin sections in control and cuprizone mice. The arrowhead and arrow indicate transverse or longitudinal sections of an axon, respectively. Scale bar $=50 \mu \mathrm{m}$. 
(A)

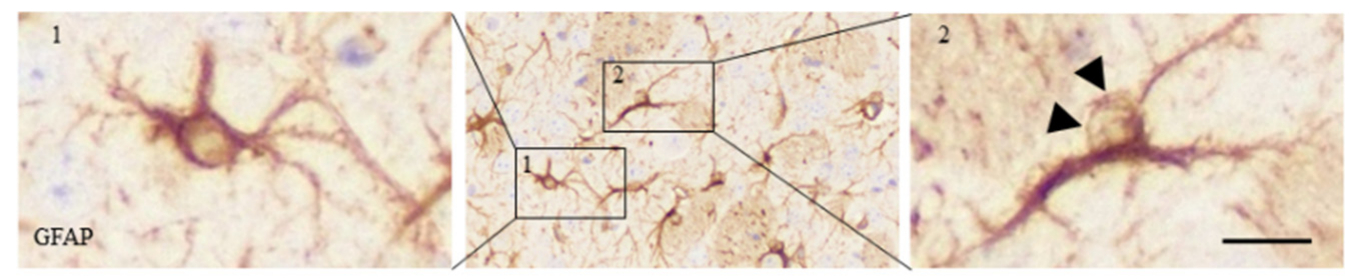

(B)
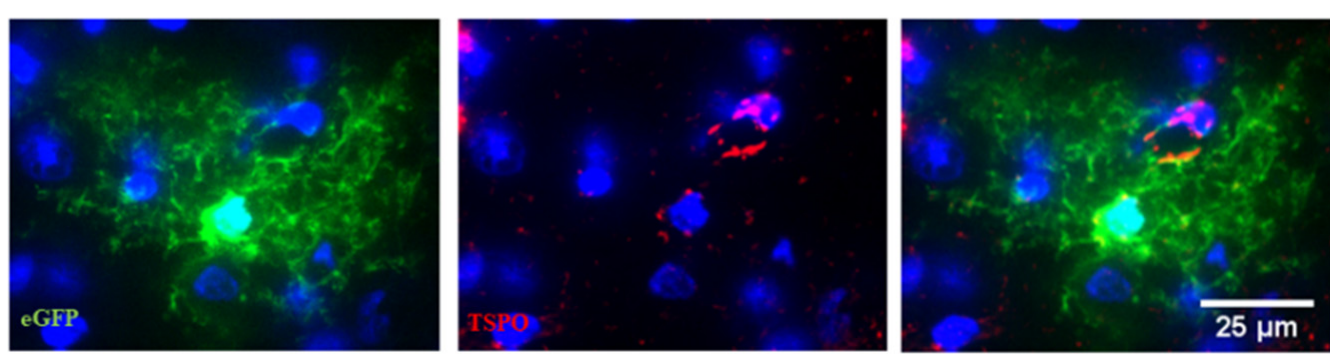

Figure 5. Astrocyte morphology. (A) Two anti-GFAP positive cells are demonstrated. Cell 1 shows anti-GFAP immunoreactivity within the entire perinuclear space, which allows for clear definition of the astrocytic cell body. Cell 2 shows anti-GFAP immunoreactivity at just one site of the cell body, making it difficult to clearly delineate the astrocyte cell body (highlighted by arrowheads). Scale bar $=20 \mu \mathrm{m}$ (center), $10 \mu \mathrm{m}$ (left, right). (B) Expression of the mitochondrial protein TSPO (red) in eGFP-expressing astrocytes. Adopted from [48]. Scale-bar $=25 \mu \mathrm{m}$. Abbreviations: glial fibrillary acidic protein (GFAP), translocator protein (TSPO), enhanced green fluorescent protein (eGFP).

\subsection{Weeks $1-3$}

As pointed out above, the first week of cuprizone intoxication is dominated by oligodendrocyte apoptosis, paralleled by the early activation of astrocytes and microglia. Anti-myelin stains do not show any abnormalities at this early stage. Between weeks 1 and 3, the degeneration of oligodendrocytes continues, paralleled by a more severe accumulation of astrocytes and microglia cells. At the end of week 3, the first signs of commencing demyelination become evident (see Figure 4A). Of note, the pathology of the myelin sheath is, at week 3 , easier to visualize by histochemical stains (e.g., by the Luxol fast blue (LFB)/periodic acid-Schiff (PAS) stain), compared to immunohistochemical approaches. As recently demonstrated by our group, the optical density within the corpus callosum of anti-proteolipid protein (PLP), anti-myelin-associated glycoprotein (MAG), and anti-2', 3'-Cyclic-nucleotide 3'-phosphodiesterase (CNPase) processed sections did show only minor differences between the control and 3 week cuprizone-intoxicated mice [50]. In contrast, myelin pathology was clearly visible by LFB/PAS stains and ultrastructural studies [34]. At this time point, the loss of mature oligodendrocytes is severe and paralleled by first but clear signs of acute axonal pathology.

As demonstrated in Figure 4A, astrocyte and microglia reactivity are already severe at week 3, which makes their quantification by counting single cells challenging or even impossible. Therefore, we suggest densitometric analyses of staining intensities as the method of choice to quantify astrocyte and microglia activation, at least in the affected corpus callosum. In the cortex and other grey matter regions, microglia and astrocyte activation is less severe [51,52], and therefore the quantification of cell numbers and cell morphology might still be feasible. Acute axonal injury is commonly visualized in anti-amyloid precursor protein (APP)-processed sections. APP is an integral glycoprotein type 1 , which is synthetized in the neuronal soma and then transported to the axonal terminal via the anterograde axonal transport machinery [53]. In case of a disturbed axonal transport machinery, APP accumulates at the sites of axonal injury, and can be visualized by immunohistochemistry as 
spheroids [54,55]. Of note, the focal accumulation of APP has also been observed in MS lesions and other animal models of MS $[4,56]$. A recent study of our group showed that both vesicular and mitochondrial proteins accumulate as spheroids at sites of acute axonal injury in the cuprizone model [57]. Thus, the visualization of acute axonal injury can as well be performed with antibodies specific for synaptic vesicles (e.g., anti-VGLUT1) or integral mitochondrial proteins (e.g., anti-VDAC1 or anti-COX4). If one quantifies the number of axonal spheroids, a nuclear stain is absolutely required. Both APP and mitochondrial proteins are not just expressed in the axonal compartment, but also in astrocytes, microglia, and oligodendrocytes. To be able to decide whether a "spheroid" belongs to an axon or a glia cell body, the spatial relation to a nucleus is extremely helpful. Just spheroids with no spatial relation to a nucleus should be counted (see Figure 6A for an example). Furthermore, very small dots should also be excluded from the analyses, since these could represent mitochondria or APP in thick glia cell processes.

(A)
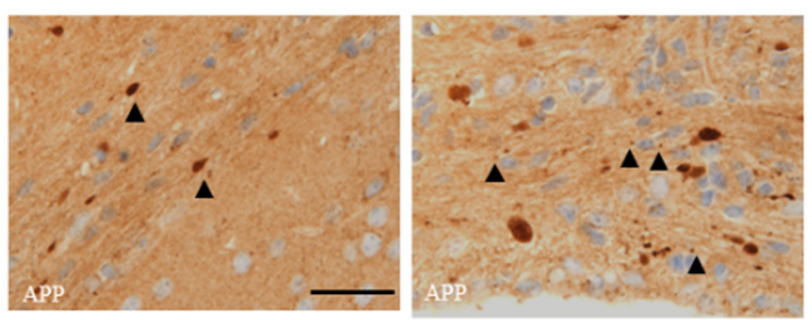

(B)
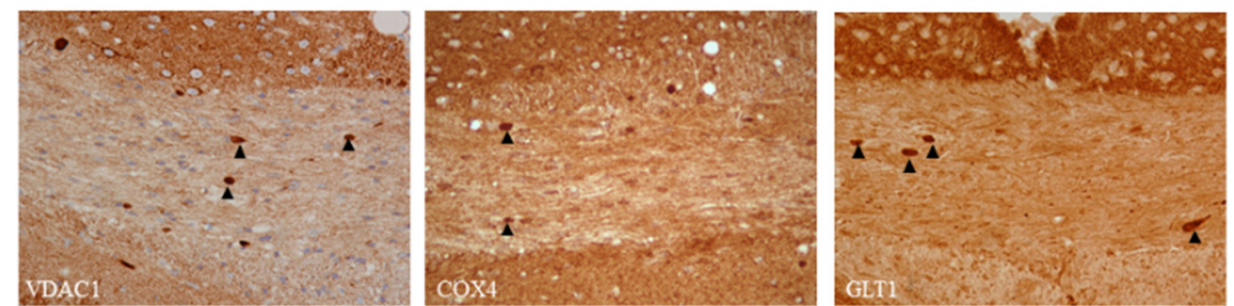

Figure 6. Acute axonal injury. (A) Acute axonal injury after 5 weeks of cuprizone intoxication, visualized by anti-APP stains. Arrowheads in the left image highlight APP spheroids. Arrowheads in the right image highlight small $\mathrm{APP}^{+}$particles in close vicinity to a cell nucleus. These small $\mathrm{APP}^{+}$ particles might belong to glia cells rather than axons. (B) Acute axonal injury visualized by the two mitochondrial-specific antibodies anti-VDAC1 and anti-COX4, as well as the synaptic protein specific antibody anti-GLT1. Arrowheads highlight the sites of acute axonal injury, indicated by a breakdown of the anterograde axonal transport machinery. Scale bar $=30 \mu \mathrm{m}$. Abbreviations: amyloid precursor protein (APP), voltage-dependent anion-selective channel 1 (VDAC1), cytochrome c oxidase subunit 4 (COX4), glutamate transporter 1 (GLT1).

\subsection{Weeks 3-5}

Between week 3 and week 5, microglia gain their full activation status and phagocytose the myelin sheaths. Astrocytosis, microgliosis, and acute axonal injury become more severe, and demyelination becomes clearly visible by immunohistochemistry. Demyelination can also be demonstrated in semi-thin processed sections (see Figure 4C) or by ultrastructural analyses [58-62]. This demyelination, together with astrocytosis and microgliosis, triggers the activation and recruitment of OPCs. Therefore, it is not surprising that the number of OLIG2 ${ }^{+}$cells after a 5 week cuprizone intoxication period is similar or even increased compared to control animals. At least during the acute stage of cuprizone-induced demyelination, these new OPCs are believed to originate from both the subventricular zones and the corpus callosum parenchyma [63]. While discussing mechanisms involved in oligodendrocyte differentiation, particularly in the cuprizone model, is out of the scope of this article, we refer to previously published articles addressing this important aspect [47,64].

Although not in the focus of this review article, numerous studies have demonstrated functional deficits induced by cuprizone intoxication. For example, demyelination of the corpus callosum has 
been linked with impaired motor coordination [65-68]. Motor deficits persist or are only partially recovered during remyelination, which is measured by different testing paradigms, such as the motor skill sequence test (MOSS), the rotarod test, or the beam cross test [69-71]. Mice also showed impaired spatial memory and a changed social behavior after cuprizone intoxication $[65,72,73]$. For a more in-depth discussion on behavioral deficits in the cuprizone model, we refer to an excellent recently published article [22].

We finally would like to point out that the perfect animal model for MS does not exist. Due to the manifold and heterogeneous pathological processes in MS, each singular animal model allows us to study very distinct aspects of the disease, rather than its entire complexity. Some of the aspects of progressive MS that can be re-capitulated in the cuprizone model are listed in Table 2. A comparison of histopathological characteristics between different MS animal models is given in $[6,74,75]$.

Table 2. Comparison between histopathological hallmarks of progressive MS and the cuprizone model. BBB: blood brain barrier.

\begin{tabular}{|c|c|c|c|}
\hline $\begin{array}{l}\text { Histopathology of } \\
\text { Progressive MS }\end{array}$ & Reference & Cuprizone Model & Reference \\
\hline $\begin{array}{l}\text { Gray matter } \\
\text { demyelination }\end{array}$ & {$[5,76]$} & $\begin{array}{l}\text { Demyelination in cortical and } \\
\text { subcortical structures }\end{array}$ & {$[77,78]$} \\
\hline $\begin{array}{l}\text { Diffuse white matter } \\
\text { damage }\end{array}$ & {$[76,79]$} & $\begin{array}{c}\text { Demyelination of white matter } \\
\text { tracts, especially in the corpus } \\
\text { callosum }\end{array}$ & {$[78,80]$} \\
\hline Axonal damage & [81-83] & $\begin{array}{l}\text { Axonal damage in } \\
\text { demyelinated areas }\end{array}$ & {$[56,84]$} \\
\hline $\begin{array}{l}\text { Minor immune cell } \\
\text { infiltration }\end{array}$ & {$[85,86]$} & $\begin{array}{l}\text { Little or no infiltration of } \\
\text { lymphocytes }\end{array}$ & {$[87,88]$} \\
\hline Minor BBB integrity loss & [89-91] & Minor BBB integrity loss & {$[22,23]$} \\
\hline $\begin{array}{l}\text { Profound oxidative } \\
\text { injury }\end{array}$ & [92-94] & $\begin{array}{c}\text { Accumulation of oxidative } \\
\text { damage }\end{array}$ & {$[95,96]$} \\
\hline $\begin{array}{l}\text { Progressive worsening of } \\
\text { function }\end{array}$ & {$[97,98]$} & $\begin{array}{c}\text { Impaired motor coordination, } \\
\text { spatial memory and social } \\
\text { behavior }\end{array}$ & {$[22,50,65-70,72,73]$} \\
\hline
\end{tabular}

\section{Dos and Do Nots in the Cuprizone Model}

After having addressed the histological characteristics of the cuprizone model and having discussed how different cellular parameters are best quantified, we next aim to list some "dos and do nots" during experimental planning, conduction, and evaluation.

\subsection{Animal Weight}

In most studies, cuprizone intoxication is realized via per os administration, by mixing the pulverized cuprizone into ground rodent chow. Some labs have also reported intoxicating their mice by oral gavage of solubilized cuprizone. While sex, genetic background, and age of the animals have been identified as important variables for the reproducibility and the extent of cuprizone-induced pathological changes [99-101], "weight" as a critical variable for reliable and consistent demyelination has just recently been systematically addressed. In a recent work, we have investigated this issue, and were able to show that animal weight is an important variable for reliable cuprizone-induced demyelination [102]. In our group, we obtain the most reliable results if we order male mice from the vendor at an age of 6-7 weeks with weights ranging from 18 to $20 \mathrm{~g}$. Of note, the weight of the mice should be determined after 1 week of rest, because mice show considerable weight loss due to transport-induced stress.

Especially in animal facilities with limited space, it is usually not feasible to design the experiment in a way that all mice have a similar weight at the beginning of the cuprizone-intoxication period. Therefore, one should try to balance the weight between the different study groups in such a way that 
lightweight and heavyweight mice are equally distributed among the groups. The same applies for the sex of the animals.

\subsection{Cuprizone Formulation}

In order to ensure reproducibility, a standardized cuprizone intoxication protocol is absolutely mandatory. In our lab, cuprizone-containing chow is prepared freshly every day by physically mixing cuprizone into ground rodent chow. Alternative methods, such as the provision of cuprizone-containing pellets [103-105], mixing of cuprizone into the drinking water [106], or oral gavage of dissolved cuprizone (personal communication) have successfully been applied. However, the effectiveness and reproducibility of these methods have been unknown until recently. In a recent study, we were interested in whether cuprizone-induced demyelination can be achieved in a reliable and reproducible manner by providing animals with cuprizone-containing pellets rather than preparing cuprizone daily in ground rodent chow. We were clearly able to demonstrate that although the preparation of cuprizone in ground rodent chow is laborious and bears the risk of cuprizone inhalation, it is the method of choice to achieve reproducible, demyelinated white matter lesions [107]. This observation is well in line with a report from Hagemeyer and colleagues. The authors noted that cuprizone-containing pellets, instead of cuprizone in ground chow, failed to induce consistent demyelination [68]. Why cuprizone provided in pellet formulation is not as effective as the ground rodent chow formulation remains to be clarified. It was assumed that cuprizone is heat-sensitive [47], and therefore could be partially deactivated during the pellet pressing procedure. However, Heckers and colleagues recently showed that thermal pretreatment of cuprizone neither abolished its demyelinating effects nor the glial responses in cuprizone-intoxicated mice. Thus, heat exposure does not inactivate cuprizone [108]. We have another theory about why cuprizone is less effective in pellet formulation. It is well known that cuprizone chelates copper [106]. Since copper is present in the pellet, prolonged interaction of cuprizone with this copper might inactivate cuprizone over time. In this context, it is important to notice that in our lab, the cuprizone powder is prepared freshly every day at a concentration of $0.25 \%$. A copper-mediated inactivation would, thus, also be possible during ground rodent chow formulation, in case the mixture is not prepared freshly every day. Although we do not know the exact underlying mechanisms of cuprizone activity loss in pellet formulation, we strongly suggest mixing cuprizone into ground rodent chow and preparing this mixture freshly every day. This is indeed time-consuming, but assures reproducible results and successful experiments.

\subsection{Selection of the Region of Interest for Histological Analyses}

Spatio-temporal information about lesion development and progression is an indispensable prerequisite for straightforward de- and remyelination studies. In contrast to the autoimmune-driven EAE model, the site of lesion development in the cuprizone model is highly predictive. However, not all brain regions are equally affected by the toxin. While demyelination is pronounced in the corpus callosum and somato-sensory cortex region [109], other CNS parts, such as the spinal cord [110], the cerebellum [111,112], or the internal capsule [78] are less severely affected. In most studies, the corpus callosum is defined as the region of interest (ROI) in this model. Of note, and this aspect of the model is very important for reliable histological evaluations, not the entire corpus callosum gets demyelinated during the course of the cuprizone intoxication. For example, at the level of the rostral corpus callosum, demyelination is severe and almost complete within the lateral parts, whereas demyelination is incomplete and inconsistent within the midline of the corpus callosum. In contrast, at more occipital levels, such as the body part of the corpus callosum, lateral parts are less severely affected, but demyelination is severe and reproducible within its midline (see Figure 7B, arrowheads). It is therefore mandatory to compare equal brain levels between the different experimental animals. In our lab, we usually analyze two distinct brain regions, which can be outlined very clearly in the coronal processed brain. The first region is at the level of the anterior commissure (slide 53 in the reference Allen Brain atlas [113] or slide 215 in the High Resolution Mouse Brain Atlas by Sidmann et 
al., [114]). At this brain level, the olfactory limbs of the anterior commissure merge within the midline of the brain, and thus, topographically define a well-demarcated level of the mouse brain (Figure 7A). At the level of the anterior commissure, we suggest separately analyzing both medial and lateral aspects of the corpus callosum. The borders of the cingulum provide a good separation of both parts (dashed line in Figure 7A). The second region is at the level of the rostral hippocampus (slide 64 in the reference Allen Brain atlas or slide 265 in the High Resolution Mouse Brain Atlas by Sidmann et al.), just where the pyramidal layer of the hippocampal cornu ammonis region becomes visible. At the level of the rostral hippocampus, we recommend analyzing the midline of the corpus callosum. In a recently published manuscript from our group, we have tried to mathematically define which part of the midline of the corpus callosum is most severely affected. This study revealed that the first five sectors, compromising a distance of $500 \mu \mathrm{m}$ from the midline of the corpus callosum, showed most severe demyelination in three different immunohistochemical stains, whereas more laterally-orientated sectors showed incomplete demyelination [50]. The neuroanatomical topography of the corpus callosum and neighboring structures are also highly relevant for an accurate histological evaluation of brain sections. Directly beneath the corpus callosum runs the hippocampal fornix. While demyelination is severe within the medial parts of the corpus callosum, loss of myelin staining intensity is by far less severe in the underlying white matter tract fornix [80]. This study clearly demonstrates that neighboring white matter tracts of the corpus callosum display distinct vulnerability to cuprizone-induced demyelination, and this has direct relevance for evaluation strategies in this frequently used MS animal model.

(A)

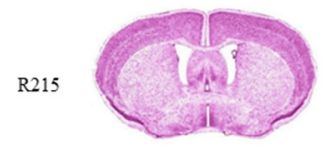

(B)

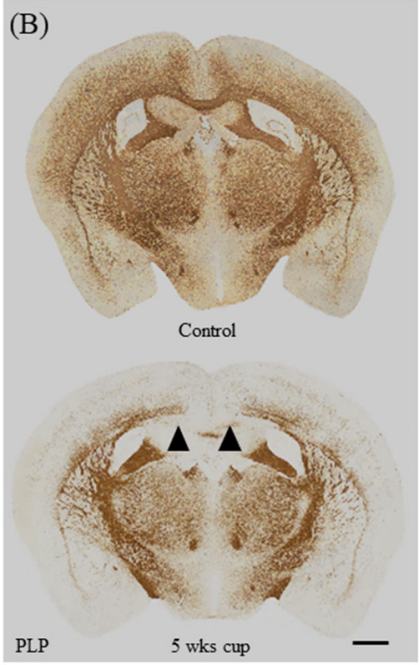

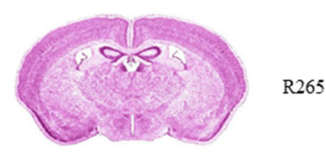

(C)
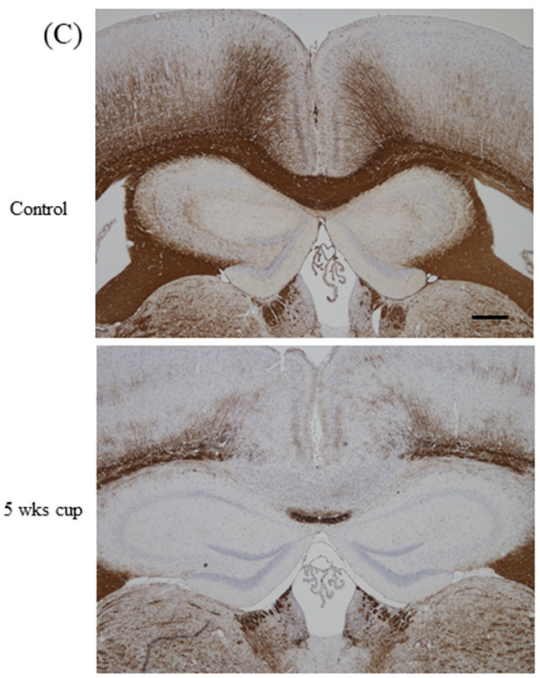
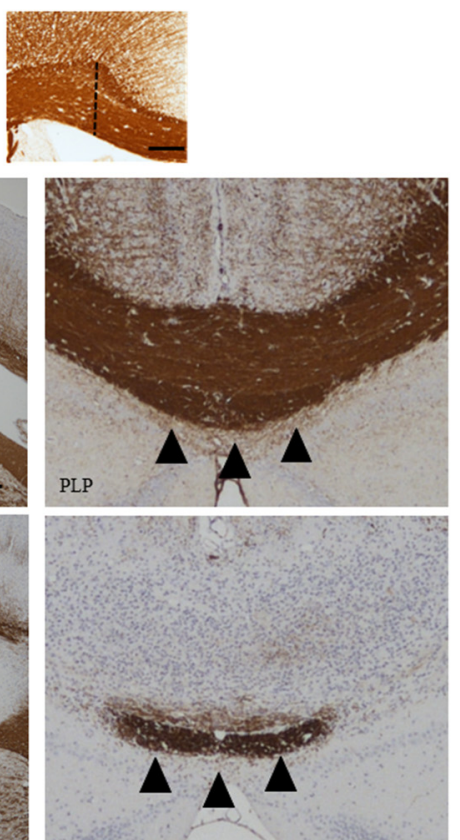

Figure 7. Topographical aspects. (A) Principal regions suggested by the authors for histopathological analyses. As shown in the right image, the tip of the cingulum provides a good anatomical border to delineate the lateral border of the midline of the corpus callosum at the level of the anterior commissure (i.e., R215). Scale-bar $=1300 \mu \mathrm{m}$ (left, center); $150 \mu \mathrm{m}$ (right). (B) Overview of anti-PLP stained sections at the level of the rostral hippocampus from control and 5 week cuprizone-intoxicated mice. The arrowheads highlight severe demyelination of the midline corpus callosum. Scale bar = $650 \mu \mathrm{m}$. (C) Overview and high magnification of anti-PLP stained sections from control and 5 week cuprizone-intoxicated mice. Arrowheads highlight the fornix, which is somewhat resistant to the cuprizone intoxication. Scale bar $=300 \mu \mathrm{m}$ (left column); $600 \mu \mathrm{m}$ (right column). Abbreviations: myelin proteolipid protein (PLP). 


\section{Conclusions}

The cuprizone model is an elegant and straightforward-to-apply tool to study different aspects of the MS pathology. In particular, different aspects of progressive MS pathological characteristics are nicely recapitulated by the cuprizone-induced pathology. Similarities between the cuprizone model and progressive MS pathology are innately driven myelin and axonal injury, functional activation of oxidative stress pathways [96], and relative preservation of the blood-brain barrier. Although out of the scope of this review article, recent results have shown that the cuprizone model, if combined with active or passive EAE induction, is an elegant tool to study the relevance of brain-intrinsic degenerative events for peripheral immune cell recruitment $[115,116]$. A better understanding of factors regulating the various histopathological aspects of the cuprizone intoxication will thus potentially pave the way for the development of novel therapeutic strategies in MS patients.

Supplementary Materials: The following are available online at http://www.mdpi.com/2073-4409/9/4/843/s1.

Author Contributions: M.K., M.F. and J.Z. designed the concept of the present study and supervised it. J.Z., T.M., S.J., and N.B. performed data analyses. M.K. and M.F. critically revised the article for important intellectual content. All authors have read and agreed to the published version of the manuscript.

Funding: This research received no external funding.

Acknowledgments: J.Z. is financially supported by the China Scholarship Council for a living stipend (CSC201706010354). We thank Helmut Kettenmann and Christiane Nolte (Max Delbrueck Center for Molecular Medicine in the Helmholtz Association, Berlin) for providing the hGFAP-eGFP mice. We thank Julia Nedelcu for providing the anti-ATF3 stained sections. We thank Tanja Hochstrasser for providing images illustrating anterograde axonal transport deficits. We thank Ute Schulz for assistance in preparing the semi-thin sections.

Conflicts of Interest: The authors declare no conflict of interest.

\section{References}

1. Carassiti, D.; Altmann, D.R.; Petrova, N.; Pakkenberg, B.; Scaravilli, F.; Schmierer, K. Neuronal loss, demyelination and volume change in the multiple sclerosis neocortex. Neuropathol. Appl. Neurobiol. 2018, 44, 377-390. [CrossRef] [PubMed]

2. Dutta, R.; Chang, A.; Doud, M.K.; Kidd, G.J.; Ribaudo, M.V.; Young, E.A.; Fox, R.J.; Staugaitis, S.M.; Trapp, B.D. Demyelination causes synaptic alterations in hippocampi from multiple sclerosis patients. Ann. Neurol. 2011, 69, 445-454. [CrossRef] [PubMed]

3. Jurgens, T.; Jafari, M.; Kreutzfeldt, M.; Bahn, E.; Bruck, W.; Kerschensteiner, M.; Merkler, D. Reconstruction of single cortical projection neurons reveals primary spine loss in multiple sclerosis. Brain 2016, 139, 39-46. [CrossRef] [PubMed]

4. Trapp, B.D.; Peterson, J.; Ransohoff, R.M.; Rudick, R.; Mork, S.; Bo, L. Axonal transection in the lesions of multiple sclerosis. New Engl. J. Med. 1998, 338, 278-285. [CrossRef] [PubMed]

5. Peterson, J.W.; Bo, L.; Mork, S.; Chang, A.; Trapp, B.D. Transected neurites, apoptotic neurons, and reduced inflammation in cortical multiple sclerosis lesions. Ann. Neurol. 2001, 50, 389-400. [CrossRef]

6. Kipp, M.; Nyamoya, S.; Hochstrasser, T.; Amor, S. Multiple sclerosis animal models: A clinical and histopathological perspective. Brain Pathol. 2017, 27, 123-137. [CrossRef]

7. Naldi, P.; Collimedaglia, L.; Vecchio, D.; Rosso, M.G.; Perl, F.; Stecco, A.; Monaco, F.; Leone, M.A. Predictors of attack severity and duration in multiple sclerosis: A prospective study. Open Neurol. J. 2011, 5, 75-82. [CrossRef]

8. Siffrin, V.; Radbruch, H.; Glumm, R.; Niesner, R.; Paterka, M.; Herz, J.; Leuenberger, T.; Lehmann, S.M.; Luenstedt, S.; Rinnenthal, J.L.; et al. In vivo imaging of partially reversible th17 cell-induced neuronal dysfunction in the course of encephalomyelitis. Immunity 2010, 33, 424-436. [CrossRef]

9. Aktas, O.; Smorodchenko, A.; Brocke, S.; Infante-Duarte, C.; Schulze Topphoff, U.; Vogt, J.; Prozorovski, T.; Meier, S.; Osmanova, V.; Pohl, E.; et al. Neuronal damage in autoimmune neuroinflammation mediated by the death ligand TRAIL. Neuron 2005, 46, 421-432. [CrossRef]

10. Trapp, B.D.; Stys, P.K. Virtual hypoxia and chronic necrosis of demyelinated axons in multiple sclerosis. Lancet Neurol. 2009, 8, 280-291. [CrossRef] 
11. Funfschilling, U.; Supplie, L.M.; Mahad, D.; Boretius, S.; Saab, A.S.; Edgar, J.; Brinkmann, B.G.; Kassmann, C.M.; Tzvetanova, I.D.; Mobius, W.; et al. Glycolytic oligodendrocytes maintain myelin and long-term axonal integrity. Nature 2012, 485, 517-521. [CrossRef] [PubMed]

12. Smith, K.J. Sodium channels and multiple sclerosis: Roles in symptom production, damage and therapy. Brain Pathol. 2007, 17, 230-242. [CrossRef] [PubMed]

13. Huynh, J.L.; Garg, P.; Thin, T.H.; Yoo, S.; Dutta, R.; Trapp, B.D.; Haroutunian, V.; Zhu, J.; Donovan, M.J.; Sharp, A.J.; et al. Epigenome-wide differences in pathology-free regions of multiple sclerosis-affected brains. Nat. Neurosci. 2014, 17, 121-130. [CrossRef] [PubMed]

14. Elkjaer, M.L.; Frisch, T.; Reynolds, R.; Kacprowski, T.; Burton, M.; Kruse, T.A.; Thomassen, M.; Baumbach, J.; Illes, Z. Unique RNA signature of different lesion types in the brain white matter in progressive multiple sclerosis. Acta Neuropathol. Commun. 2019, 7, 58. [CrossRef]

15. Behrangi, N.; Fischbach, F.; Kipp, M. Mechanism of Siponimod: Anti-Inflammatory and Neuroprotective Mode of Action. Cells 2019, 8, 24. [CrossRef]

16. Kappos, L.; Bar-Or, A.; Cree, B.A.C.; Fox, R.J.; Giovannoni, G.; Gold, R.; Vermersch, P.; Arnold, D.L.; Arnould, S.; Scherz, T.; et al. Siponimod versus placebo in secondary progressive multiple sclerosis (EXPAND): A double-blind, randomised, phase 3 study. Lancet 2018, 391, 1263-1273. [CrossRef]

17. Tremlett, H.; Zhao, Y.; Joseph, J.; Devonshire, V. Relapses in multiple sclerosis are age- and time-dependent. J. Neurol. Neurosurg. Psychiatry 2008, 79, 1368-1374. [CrossRef]

18. Bolton, C.; Smith, P.A. The influence and impact of ageing and immunosenescence (ISC) on adaptive immunity during multiple sclerosis (MS) and the animal counterpart experimental autoimmune encephalomyelitis (EAE). Ageing Res. Rev. 2018, 41, 64-81. [CrossRef]

19. Penner, I.K.; Aktas, O. Functional reorganization is a maladaptive response to injury-NO. Mult. Scler. 2017, 23, 193-194. [CrossRef]

20. Enzinger, C.; Pinter, D.; Rocca, M.A.; De Luca, J.; Sastre-Garriga, J.; Audoin, B.; Filippi, M. Longitudinal fMRI studies: Exploring brain plasticity and repair in MS. Mult. Scler. 2016, 22, 269-278. [CrossRef]

21. Kipp, M.; Clarner, T.; Dang, J.; Copray, S.; Beyer, C. The cuprizone animal model: New insights into an old story. Acta Neuropathol. 2009, 118, 723-736. [CrossRef]

22. Praet, J.; Guglielmetti, C.; Berneman, Z.; Van der Linden, A.; Ponsaerts, P. Cellular and molecular neuropathology of the cuprizone mouse model: Clinical relevance for multiple sclerosis. Neurosci. Biobehav. Rev. 2014, 47, 485-505. [CrossRef]

23. Berghoff, S.A.; Duking, T.; Spieth, L.; Winchenbach, J.; Stumpf, S.K.; Gerndt, N.; Kusch, K.; Ruhwedel, T.; Mobius, W.; Saher, G. Blood-brain barrier hyperpermeability precedes demyelination in the cuprizone model. Acta Neuropathol. Commun. 2017, 5, 94. [CrossRef]

24. Wolf, Y.; Shemer, A.; Levy-Efrati, L.; Gross, M.; Kim, J.S.; Engel, A.; David, E.; Chappell-Maor, L.; Grozovski, J.; Rotkopf, R.; et al. Microglial MHC class II is dispensable for experimental autoimmune encephalomyelitis and cuprizone-induced demyelination. Eur. J. Immunol. 2018, 48, 1308-1318. [CrossRef]

25. Hiremath, M.M.; Chen, V.S.; Suzuki, K.; Ting, J.P.; Matsushima, G.K. MHC class II exacerbates demyelination in vivo independently of T cells. J. Neuroimmunol. 2008, 203, 23-32. [CrossRef] [PubMed]

26. Slowik, A.; Schmidt, T.; Beyer, C.; Amor, S.; Clarner, T.; Kipp, M. The sphingosine 1-phosphate receptor agonist FTY720 is neuroprotective after cuprizone-induced CNS demyelination. Br. J. Pharmacol. 2015, 172, 80-92. [CrossRef] [PubMed]

27. Voskuhl, R.R.; Itoh, N.; Tassoni, A.; Matsukawa, M.A.; Ren, E.; Tse, V.; Jang, E.; Suen, T.T.; Itoh, Y. Gene expression in oligodendrocytes during remyelination reveals cholesterol homeostasis as a therapeutic target in multiple sclerosis. Proc. Natl. Acad. Sci. USA 2019, 116, 10130-10139. [CrossRef] [PubMed]

28. Lindner, M.; Fokuhl, J.; Linsmeier, F.; Trebst, C.; Stangel, M. Chronic toxic demyelination in the central nervous system leads to axonal damage despite remyelination. Neurosci. Lett. 2009, 453, 120-125. [CrossRef]

29. Zendedel, A.; Beyer, C.; Kipp, M. Cuprizone-induced demyelination as a tool to study remyelination and axonal protection. J. Mol. Neurosci. 2013, 51, 567-572. [CrossRef]

30. Kipp, M. Remyelination strategies in multiple sclerosis: A critical reflection. Expert Rev. Neurother. 2016, 16, 1-3. [CrossRef]

31. Shields, S.A.; Gilson, J.M.; Blakemore, W.F.; Franklin, R.J. Remyelination occurs as extensively but more slowly in old rats compared to young rats following gliotoxin-induced CNS demyelination. Glia 1999, 28, 77-83. [CrossRef] 
32. Nicaise, A.M.; Wagstaff, L.J.; Willis, C.M.; Paisie, C.; Chandok, H.; Robson, P.; Fossati, V.; Williams, A.; Crocker, S.J. Cellular senescence in progenitor cells contributes to diminished remyelination potential in progressive multiple sclerosis. Proc. Natl. Acad. Sci. USA 2019, 116, 9030-9039. [CrossRef] [PubMed]

33. Baror, R.; Neumann, B.; Segel, M.; Chalut, K.J.; Fancy, S.P.J.; Schafer, D.P.; Franklin, R.J.M. Transforming growth factor-beta renders ageing microglia inhibitory to oligodendrocyte generation by CNS progenitors. Glia 2019, 67, 1374-1384. [CrossRef] [PubMed]

34. Fischbach, F.; Nedelcu, J.; Leopold, P.; Zhan, J.; Clarner, T.; Nellessen, L.; Beissel, C.; van Heuvel, Y.; Goswami, A.; Weis, J.; et al. Cuprizone-induced graded oligodendrocyte vulnerability is regulated by the transcription factor DNA damage-inducible transcript 3. Glia 2019, 67, 263-276. [CrossRef] [PubMed]

35. Krauspe, B.M.; Dreher, W.; Beyer, C.; Baumgartner, W.; Denecke, B.; Janssen, K.; Langhans, C.D.; Clarner, T.; Kipp, M. Short-term cuprizone feeding verifies $\mathrm{N}$-acetylaspartate quantification as a marker of neurodegeneration. J. Mol. Neurosci. 2015, 55, 733-748. [CrossRef]

36. Zhang, Y.; Chen, K.; Sloan, S.A.; Bennett, M.L.; Scholze, A.R.; O’Keeffe, S.; Phatnani, H.P.; Guarnieri, P.; Caneda, C.; Ruderisch, N.; et al. An RNA-sequencing transcriptome and splicing database of glia, neurons, and vascular cells of the cerebral cortex. J. Neurosci. 2014, 34, 11929-11947. [CrossRef]

37. Kim, W.K.; Kim, D.; Cui, J.; Jang, H.H.; Kim, K.S.; Lee, H.J.; Kim, S.U.; Ahn, S.M. Secretome analysis of human oligodendrocytes derived from neural stem cells. PLoS ONE 2014, 9, e84292. [CrossRef]

38. Kipp, M.; Gingele, S.; Pott, F.; Clarner, T.; van der Valk, P.; Denecke, B.; Gan, L.; Siffrin, V.; Zipp, F.; Dreher, W.; et al. BLBP-expression in astrocytes during experimental demyelination and in human multiple sclerosis lesions. Brain Behav. Immun. 2011, 25, 1554-1568. [CrossRef]

39. Sakamoto, Y.; Boeda, B.; Etienne-Manneville, S. APC binds intermediate filaments and is required for their reorganization during cell migration. J. Cell Biol. 2013, 200, 249-258. [CrossRef]

40. Lee, H.N.; Jeon, G.S.; Kim, D.W.; Cho, I.H.; Cho, S.S. Expression of adenomatous polyposis coli protein in reactive astrocytes in hippocampus of kainic acid-induced rat. Neurochem. Res. 2010, 35, 114-121. [CrossRef]

41. Salinas Tejedor, L.; Gudi, V.; Kucman, V.; Pul, R.; Gingele, S.; Suhs, K.W.; Stangel, M.; Skripuletz, T. Oligodendroglial markers in the cuprizone model of CNS de- and remyelination. Histol. Histopathol. 2015, 30, 1455-1464. [CrossRef] [PubMed]

42. Buschmann, J.P.; Berger, K.; Awad, H.; Clarner, T.; Beyer, C.; Kipp, M. Inflammatory response and chemokine expression in the white matter corpus callosum and gray matter cortex region during cuprizone-induced demyelination. J. Mol. Neurosci. 2012, 48, 66-76. [CrossRef] [PubMed]

43. Li, Q.; Barres, B.A. Microglia and macrophages in brain homeostasis and disease. Nat. Rev. Immunol. 2018, 18, 225-242. [CrossRef] [PubMed]

44. Ginhoux, F.; Greter, M.; Leboeuf, M.; Nandi, S.; See, P.; Gokhan, S.; Mehler, M.F.; Conway, S.J.; Ng, L.G.; Stanley, E.R.; et al. Fate mapping analysis reveals that adult microglia derive from primitive macrophages. Science 2010, 330, 841-845. [CrossRef]

45. Kierdorf, K.; Erny, D.; Goldmann, T.; Sander, V.; Schulz, C.; Perdiguero, E.G.; Wieghofer, P.; Heinrich, A.; Riemke, P.; Holscher, C.; et al. Microglia emerge from erythromyeloid precursors via Pu.1- and Irf8-dependent pathways. Nat. Neurosci. 2013, 16, 273-280. [CrossRef]

46. Van Hove, H.; Martens, L.; Scheyltjens, I.; De Vlaminck, K.; Pombo Antunes, A.R.; De Prijck, S.; Vandamme, N.; De Schepper, S.; Van Isterdael, G.; Scott, C.L.; et al. A single-cell atlas of mouse brain macrophages reveals unique transcriptional identities shaped by ontogeny and tissue environment. Nat. Neurosci. 2019, 22, 1021-1035. [CrossRef]

47. Gudi, V.; Gingele, S.; Skripuletz, T.; Stangel, M. Glial response during cuprizone-induced de- and remyelination in the CNS: Lessons learned. Front. Cell. Neurosci. 2014, 8, 73. [CrossRef]

48. Nack, A.; Brendel, M.; Nedelcu, J.; Daerr, M.; Nyamoya, S.; Beyer, C.; Focke, C.; Deussing, M.; Hoornaert, C.; Ponsaerts, P.; et al. Expression of Translocator Protein and [18F]-GE180 Ligand Uptake in Multiple Sclerosis Animal Models. Cells 2019, 8, 94. [CrossRef]

49. Nolte, C.; Matyash, M.; Pivneva, T.; Schipke, C.G.; Ohlemeyer, C.; Hanisch, U.K.; Kirchhoff, F.; Kettenmann, H. GFAP promoter-controlled EGFP-expressing transgenic mice: A tool to visualize astrocytes and astrogliosis in living brain tissue. Glia 2001, 33, 72-86. [CrossRef]

50. Chrzanowski, U.; Schmitz, C.; Horn-Bochtler, A.; Nack, A.; Kipp, M. Evaluation strategy to determine reliable demyelination in the cuprizone model. Metab. Brain Dis. 2019, 34, 681-685. [CrossRef] 
51. Grosse-Veldmann, R.; Becker, B.; Amor, S.; van der Valk, P.; Beyer, C.; Kipp, M. Lesion Expansion in Experimental Demyelination Animal Models and Multiple Sclerosis Lesions. Mol. Neurobiol. 2016, 53, 4905-4917. [CrossRef] [PubMed]

52. Clarner, T.; Diederichs, F.; Berger, K.; Denecke, B.; Gan, L.; van der Valk, P.; Beyer, C.; Amor, S.; Kipp, M. Myelin debris regulates inflammatory responses in an experimental demyelination animal model and multiple sclerosis lesions. Glia 2012, 60, 1468-1480. [CrossRef] [PubMed]

53. Koo, E.H.; Sisodia, S.S.; Archer, D.R.; Martin, L.J.; Weidemann, A.; Beyreuther, K.; Fischer, P.; Masters, C.L.; Price, D.L. Precursor of amyloid protein in Alzheimer disease undergoes fast anterograde axonal transport. Proc. Natl. Acad. Sci. USA 1990, 87, 1561-1565. [CrossRef] [PubMed]

54. Sherriff, F.E.; Bridges, L.R.; Gentleman, S.M.; Sivaloganathan, S.; Wilson, S. Markers of axonal injury in post mortem human brain. Acta Neuropathol. 1994, 88, 433-439. [CrossRef]

55. Stone, J.R.; Singleton, R.H.; Povlishock, J.T. Antibodies to the C-terminus of the beta-amyloid precursor protein (APP): A site specific marker for the detection of traumatic axonal injury. Brain Res. 2000, 871, 288-302. [CrossRef]

56. Hoflich, K.M.; Beyer, C.; Clarner, T.; Schmitz, C.; Nyamoya, S.; Kipp, M.; Hochstrasser, T. Acute axonal damage in three different murine models of multiple sclerosis: A comparative approach. Brain Res. 2016, 1650, 125-133. [CrossRef]

57. Ruhling, S.; Kramer, F.; Schmutz, S.; Amor, S.; Jiangshan, Z.; Schmitz, C.; Kipp, M.; Hochstrasser, T. Visualization of the Breakdown of the Axonal Transport Machinery: A Comparative Ultrastructural and Immunohistochemical Approach. Mol. Neurobiol. 2019, 56, 3984-3998. [CrossRef]

58. Thiessen, J.D.; Zhang, Y.; Zhang, H.; Wang, L.; Buist, R.; Del Bigio, M.R.; Kong, J.; Li, X.M.; Martin, M. Quantitative MRI and ultrastructural examination of the cuprizone mouse model of demyelination. NMR Biomed. 2013, 26, 1562-1581. [CrossRef]

59. Acs, P.; Komoly, S. Selective ultrastructural vulnerability in the cuprizone-induced experimental demyelination. Ideggyogy. Szle. 2012, 65, 266-270.

60. Wergeland, S.; Torkildsen, O.; Myhr, K.M.; Mork, S.J.; Bo, L. The cuprizone model: Regional heterogeneity of pathology. APMIS 2012, 120, 648-657. [CrossRef]

61. Torkildsen, O.; Brunborg, L.A.; Myhr, K.M.; Bo, L. The cuprizone model for demyelination. Acta Neurol. Scand. 2008, 188, 72-76. [CrossRef] [PubMed]

62. Pfeffer, S.; Mahamid, J. Unravelling molecular complexity in structural cell biology. Curr. Opin. Struct. Biol. 2018, 52, 111-118. [CrossRef] [PubMed]

63. Brousse, B.; Magalon, K.; Durbec, P.; Cayre, M. Region and dynamic specificities of adult neural stem cells and oligodendrocyte precursors in myelin regeneration in the mouse brain. Biol. Open 2015, 4, 980-992. [CrossRef] [PubMed]

64. Tiane, A.; Schepers, M.; Rombaut, B.; Hupperts, R.; Prickaerts, J.; Hellings, N.; van den Hove, D.; Vanmierlo, T. From OPC to Oligodendrocyte: An Epigenetic Journey. Cells 2019, 8, 1236. [CrossRef]

65. Xu, H.; Yang, H.J.; McConomy, B.; Browning, R.; Li, X.M. Behavioral and neurobiological changes in C57BL/6 mouse exposed to cuprizone: Effects of antipsychotics. Front. Behav. Neurosci. 2010, 4, 8. [CrossRef]

66. Hibbits, N.; Pannu, R.; Wu, T.J.; Armstrong, R.C. Cuprizone demyelination of the corpus callosum in mice correlates with altered social interaction and impaired bilateral sensorimotor coordination. Asn Neuro 2009, 1. [CrossRef]

67. Liebetanz, D.; Merkler, D. Effects of commissural de- and remyelination on motor skill behaviour in the cuprizone mouse model of multiple sclerosis. Exp. Neurol. 2006, 202, 217-224. [CrossRef]

68. Hagemeyer, N.; Boretius, S.; Ott, C.; Von Streitberg, A.; Welpinghus, H.; Sperling, S.; Frahm, J.; Simons, M.; Ghezzi, P.; Ehrenreich, H. Erythropoietin attenuates neurological and histological consequences of toxic demyelination in mice. Mol. Med. 2012, 18, 628-635. [CrossRef]

69. Manrique-Hoyos, N.; Jurgens, T.; Gronborg, M.; Kreutzfeldt, M.; Schedensack, M.; Kuhlmann, T.; Schrick, C.; Bruck, W.; Urlaub, H.; Simons, M.; et al. Late motor decline after accomplished remyelination: Impact for progressive multiple sclerosis. Ann. Neurol. 2012, 71, 227-244. [CrossRef]

70. Franco-Pons, N.; Torrente, M.; Colomina, M.T.; Vilella, E. Behavioral deficits in the cuprizone-induced murine model of demyelination/remyelination. Toxicol. Lett. 2007, 169, 205-213. [CrossRef] 
71. Zhan, J.; Yakimov, V.; Ruhling, S.; Fischbach, F.; Nikolova, E.; Joost, S.; Kaddatz, H.; Greiner, T.; Frenz, J.; Holzmann, C.; et al. High Speed Ventral Plane Videography as a Convenient Tool to Quantify Motor Deficits during Pre-Clinical Experimental Autoimmune Encephalomyelitis. Cells 2019, 8, 1439. [CrossRef] [PubMed]

72. Makinodan, M.; Yamauchi, T.; Tatsumi, K.; Okuda, H.; Takeda, T.; Kiuchi, K.; Sadamatsu, M.; Wanaka, A.; Kishimoto, T. Demyelination in the juvenile period, but not in adulthood, leads to long-lasting cognitive impairment and deficient social interaction in mice. Prog. Neuro Psychopharmacol. Biol. Psychiatry 2009, 33, 978-985. [CrossRef]

73. Xu, H.; Yang, H.J.; Zhang, Y.; Clough, R.; Browning, R.; Li, X.M. Behavioral and neurobiological changes in C57BL/6 mice exposed to cuprizone. Behav. Neurosci. 2009, 123, 418-429. [CrossRef]

74. Procaccini, C.; De Rosa, V.; Pucino, V.; Formisano, L.; Matarese, G. Animal models of Multiple Sclerosis. Eur. J. Pharm. 2015, 759, 182-191. [CrossRef]

75. Ransohoff, R.M. Animal models of multiple sclerosis: The good, the bad and the bottom line. Nat. Neurosci. 2012, 15, 1074-1077. [CrossRef]

76. Kutzelnigg, A.; Lucchinetti, C.F.; Stadelmann, C.; Bruck, W.; Rauschka, H.; Bergmann, M.; Schmidbauer, M.; Parisi, J.E.; Lassmann, H. Cortical demyelination and diffuse white matter injury in multiple sclerosis. Brain 2005, 128, 2705-2712. [CrossRef]

77. Wagenknecht, N.; Becker, B.; Scheld, M.; Beyer, C.; Clarner, T.; Hochstrasser, T.; Kipp, M. Thalamus Degeneration and Inflammation in Two Distinct Multiple Sclerosis Animal Models. J. Mol. Neurosci. 2016, 60, 102-114. [CrossRef]

78. Goldberg, J.; Clarner, T.; Beyer, C.; Kipp, M. Anatomical Distribution of Cuprizone-Induced Lesions in C57BL6 Mice. J. Mol. Neurosci. 2015, 57, 166-175. [CrossRef] [PubMed]

79. Vrenken, H.; Seewann, A.; Knol, D.L.; Polman, C.H.; Barkhof, F.; Geurts, J.J. Diffusely abnormal white matter in progressive multiple sclerosis: In vivo quantitative MR imaging characterization and comparison between disease types. Ajnr Am. J. Neuroradiol. 2010, 31, 541-548. [CrossRef] [PubMed]

80. Schmidt, T.; Awad, H.; Slowik, A.; Beyer, C.; Kipp, M.; Clarner, T. Regional heterogeneity of cuprizone-induced demyelination: Topographical aspects of the midline of the corpus callosum. J. Mol. Neurosci. 2013, 49, 80-88. [CrossRef] [PubMed]

81. Singh, S.; Dallenga, T.; Winkler, A.; Roemer, S.; Maruschak, B.; Siebert, H.; Bruck, W.; Stadelmann, C. Relationship of acute axonal damage, Wallerian degeneration, and clinical disability in multiple sclerosis. J. Neuroinflamm. 2017, 14, 57. [CrossRef]

82. Haines, J.D.; Inglese, M.; Casaccia, P. Axonal damage in multiple sclerosis. Mt. Sinai J. Med. 2011, 78, $231-243$. [CrossRef] [PubMed]

83. Mews, I.; Bergmann, M.; Bunkowski, S.; Gullotta, F.; Bruck, W. Oligodendrocyte and axon pathology in clinically silent multiple sclerosis lesions. Mult. Scler. 1998, 4, 55-62. [CrossRef] [PubMed]

84. Ohno, N.; Chiang, H.; Mahad, D.J.; Kidd, G.J.; Liu, L.; Ransohoff, R.M.; Sheng, Z.H.; Komuro, H.; Trapp, B.D. Mitochondrial immobilization mediated by syntaphilin facilitates survival of demyelinated axons. Proc. Natl. Acad. Sci. USA 2014, 111, 9953-9958. [CrossRef] [PubMed]

85. Machado-Santos, J.; Saji, E.; Troscher, A.R.; Paunovic, M.; Liblau, R.; Gabriely, G.; Bien, C.G.; Bauer, J.; Lassmann, $\mathrm{H}$. The compartmentalized inflammatory response in the multiple sclerosis brain is composed of tissue-resident CD8+ T lymphocytes and B cells. Brain 2018, 141, 2066-2082. [CrossRef] [PubMed]

86. Lassmann, H.; Bruck, W.; Lucchinetti, C.F. The immunopathology of multiple sclerosis: An overview. Brain Pathol. 2007, 17, 210-218. [CrossRef] [PubMed]

87. Cerina, M.; Narayanan, V.; Gobel, K.; Bittner, S.; Ruck, T.; Meuth, P.; Herrmann, A.M.; Stangel, M.; Gudi, V.; Skripuletz, T.; et al. The quality of cortical network function recovery depends on localization and degree of axonal demyelination. Brain Behav. Immun. 2017, 59, 103-117. [CrossRef]

88. Remington, L.T.; Babcock, A.A.; Zehntner, S.P.; Owens, T. Microglial recruitment, activation, and proliferation in response to primary demyelination. Am. J. Pathol. 2007, 170, 1713-1724. [CrossRef]

89. Kirk, J.; Plumb, J.; Mirakhur, M.; McQuaid, S. Tight junctional abnormality in multiple sclerosis white matter affects all calibres of vessel and is associated with blood-brain barrier leakage and active demyelination. J. Pathol. 2003, 201, 319-327. [CrossRef]

90. Leech, S.; Kirk, J.; Plumb, J.; McQuaid, S. Persistent endothelial abnormalities and blood-brain barrier leak in primary and secondary progressive multiple sclerosis. Neuropathol. Appl. Neurobiol. 2007, 33, 86-98. [CrossRef] 
91. Plumb, J.; McQuaid, S.; Mirakhur, M.; Kirk, J. Abnormal endothelial tight junctions in active lesions and normal-appearing white matter in multiple sclerosis. Brain Pathol. 2002, 12, 154-169. [CrossRef] [PubMed]

92. Ohl, K.; Tenbrock, K.; Kipp, M. Oxidative stress in multiple sclerosis: Central and peripheral mode of action. Exp. Neurol. 2016, 277, 58-67. [CrossRef] [PubMed]

93. Lee, D.H.; Gold, R.; Linker, R.A. Mechanisms of oxidative damage in multiple sclerosis and neurodegenerative diseases: Therapeutic modulation via fumaric acid esters. Int. J. Mol. Sci. 2012, 13, 11783-11803. [CrossRef] [PubMed]

94. Campbell, G.R.; Ziabreva, I.; Reeve, A.K.; Krishnan, K.J.; Reynolds, R.; Howell, O.; Lassmann, H.; Turnbull, D.M.; Mahad, D.J. Mitochondrial DNA deletions and neurodegeneration in multiple sclerosis. Ann. Neurol. 2011, 69, 481-492. [CrossRef]

95. Kashani, I.R.; Chavoshi, H.; Pasbakhsh, P.; Hassani, M.; Omidi, A.; Mahmoudi, R.; Beyer, C.; Zendedel, A. Protective effects of erythropoietin against cuprizone-induced oxidative stress and demyelination in the mouse corpus callosum. Iran. J. Basic Med. Sci. 2017, 20, 886-893. [CrossRef]

96. Draheim, T.; Liessem, A.; Scheld, M.; Wilms, F.; Weissflog, M.; Denecke, B.; Kensler, T.W.; Zendedel, A.; Beyer, C.; Kipp, M.; et al. Activation of the astrocytic Nrf2/ARE system ameliorates the formation of demyelinating lesions in a multiple sclerosis animal model. Glia 2016, 64, 2219-2230. [CrossRef]

97. Filippi, M.; Bar-Or, A.; Piehl, F.; Preziosa, P.; Solari, A.; Vukusic, S.; Rocca, M.A. Multiple sclerosis. Nat. Rev. Dis. Primers 2018, 4, 43. [CrossRef]

98. Mahad, D.H.; Trapp, B.D.; Lassmann, H. Pathological mechanisms in progressive multiple sclerosis. Lancet Neurol. 2015, 14, 183-193. [CrossRef]

99. Valeiras, B.; Rosato Siri, M.V.; Codagnone, M.; Reines, A.; Pasquini, J.M. Gender influence on schizophrenia-relevant abnormalities in a cuprizone demyelination model. Glia 2014, 62, 1629-1644. [CrossRef]

100. Taylor, L.C.; Gilmore, W.; Matsushima, G.K. SJL mice exposed to cuprizone intoxication reveal strain and gender pattern differences in demyelination. Brain Pathol. 2009, 19, 467-479. [CrossRef]

101. Irvine, K.A.; Blakemore, W.F. Age increases axon loss associated with primary demyelination in cuprizone-induced demyelination in C57BL/6 mice. J. Neuroimmunol. 2006, 175, 69-76. [CrossRef] [PubMed]

102. Leopold, P.; Schmitz, C.; Kipp, M. Animal Weight Is an Important Variable for Reliable Cuprizone-Induced Demyelination. J. Mol. Neurosci. 2019, 68, 522-528. [CrossRef] [PubMed]

103. Steelman, A.J.; Thompson, J.P.; Li, J. Demyelination and remyelination in anatomically distinct regions of the corpus callosum following cuprizone intoxication. Neurosci. Res. 2012, 72, 32-42. [CrossRef]

104. Carey, E.M.; Freeman, N.M. Biochemical changes in Cuprizone-induced spongiform encephalopathy. I. Changes in the activities of $2^{\prime}, 3^{\prime}$-cyclic nucleotide $3^{\prime}$-phosphohydrolase, oligodendroglial ceramide galactosyl transferase, and the hydrolysis of the alkenyl group of alkenyl, acyl-glycerophospholipids by plasmalogenase in different regions of the brain. Neurochem. Res. 1983, 8, 1029-1044.

105. Soundarapandian, M.M.; Selvaraj, V.; Lo, U.G.; Golub, M.S.; Feldman, D.H.; Pleasure, D.E.; Deng, W. Zfp488 promotes oligodendrocyte differentiation of neural progenitor cells in adult mice after demyelination. Sci. Rep. 2011, 1, 2. [CrossRef]

106. Zatta, P.; Raso, M.; Zambenedetti, P.; Wittkowski, W.; Messori, L.; Piccioli, F.; Mauri, P.L.; Beltramini, M. Copper and zinc dismetabolism in the mouse brain upon chronic cuprizone treatment. Cell. Mol. Life Sci. CMLS 2005, 62, 1502-1513. [CrossRef]

107. Hochstrasser, T.; Exner, G.L.; Nyamoya, S.; Schmitz, C.; Kipp, M. Cuprizone-Containing Pellets Are Less Potent to Induce Consistent Demyelination in the Corpus Callosum of C57BL/6 Mice. J. Mol. Neurosci. 2017, 61, 617-624. [CrossRef]

108. Heckers, S.; Held, N.; Kronenberg, J.; Skripuletz, T.; Bleich, A.; Gudi, V.; Stangel, M. Investigation of Cuprizone Inactivation by Temperature. Neurotox. Res. 2017. [CrossRef]

109. Skripuletz, T.; Lindner, M.; Kotsiari, A.; Garde, N.; Fokuhl, J.; Linsmeier, F.; Trebst, C.; Stangel, M. Cortical demyelination is prominent in the murine cuprizone model and is strain-dependent. Am. J. Pathol. 2008, 172, 1053-1061. [CrossRef] 
110. Herder, V.; Hansmann, F.; Stangel, M.; Skripuletz, T.; Baumgartner, W.; Beineke, A. Lack of cuprizone-induced demyelination in the murine spinal cord despite oligodendroglial alterations substantiates the concept of site-specific susceptibilities of the central nervous system. Neuropathol. Appl. Neurobiol. 2011, 37, 676-684. [CrossRef]

111. Skripuletz, T.; Bussmann, J.H.; Gudi, V.; Koutsoudaki, P.N.; Pul, R.; Moharregh-Khiabani, D.; Lindner, M.; Stangel, M. Cerebellar cortical demyelination in the murine cuprizone model. Brain Pathol. 2010, 20, 301-312. [CrossRef] [PubMed]

112. Groebe, A.; Clarner, T.; Baumgartner, W.; Dang, J.; Beyer, C.; Kipp, M. Cuprizone treatment induces distinct demyelination, astrocytosis, and microglia cell invasion or proliferation in the mouse cerebellum. Cerebellum 2009, 8, 163-174. [CrossRef] [PubMed]

113. Allen Mouse Brain Atlas. Available online: https://mouse.brain-map.org/static/atlas (accessed on 31 March 2020).

114. High Resolution Mouse Brain Atlas. Available online: http://www.hms.harvard.edu/research/brain/atlas.html (accessed on 31 March 2020).

115. Ruther, B.J.; Scheld, M.; Dreymueller, D.; Clarner, T.; Kress, E.; Brandenburg, L.O.; Swartenbroekx, T.; Hoornaert, C.; Ponsaerts, P.; Fallier-Becker, P.; et al. Combination of cuprizone and experimental autoimmune encephalomyelitis to study inflammatory brain lesion formation and progression. Glia 2017, 65, 1900-1913. [CrossRef] [PubMed]

116. Scheld, M.; Ruther, B.J.; Grosse-Veldmann, R.; Ohl, K.; Tenbrock, K.; Dreymuller, D.; Fallier-Becker, P.; Zendedel, A.; Beyer, C.; Clarner, T.; et al. Neurodegeneration Triggers Peripheral Immune Cell Recruitment into the Forebrain. J. Neurosci. 2016, 36, 1410-1415. [CrossRef]

(C) 2020 by the authors. Licensee MDPI, Basel, Switzerland. This article is an open access article distributed under the terms and conditions of the Creative Commons Attribution (CC BY) license (http://creativecommons.org/licenses/by/4.0/). 